\title{
Tendencias del Third-Party Funding y su futuro en el arbitraje internacional
}

\author{
Sebastián CAMilo Camayo OrTIZ ${ }^{1}$
}

\section{RESUMEN}

En este artículo se estudia el fenómeno de la financiación por terceros en el arbitraje internacional (también conocido como Third-Party Funding o TPF) y se pretende con este entender cómo las tendencias que atraviesa el TPF en la actualidad pueden favorecer su desarrollo por los próximos diez años. Así, tras haber examinado el concepto y la evolución de la figura por medio de una revisión bibliográfica, el escrito analiza el futuro del TPF a partir de tres de sus tendencias más relevantes: I) el crecimiento exponencial en el uso de la figura, II) la entrada a nuevos mercados en los que esta era poco o nada conocida, y III) su reciente etapa de regulación. De lo anterior, se concluye que los diez años siguientes del TPF estarán probablemente marcados por su crecimiento constante, ello al no haber signos de desaceleración en su uso y consolidación en nuevos mercados. No obstante, el futuro de la figura parece estar principalmente ligado a su tendencia reguladora, ya que lograría un concepto casi universal del TPF, garantizaría la validez del fenómeno en jurisdicciones donde es prohibido al día de hoy y contribuiría a resolver las críticas existentes en su contra.

Palabras clave: financiamiento de terceros, tercero financiador, acuerdo de financiamiento, arbitraje, arbitraje internacional, arbitraje comercial internacional, arbitraje de inversiones, regulación.

1 Estudiante del programa de Derecho de la Universidad del Cauca (Colombia) y miembro del Semillero de Investigación en Derecho Procesal Jesús Hernando Segura de la misma universidad. Correo electrónico: sebascamayo@unicauca.edu.co. ORCID: https://orcid.org/0000-0001-7801-3184.

* DOI: https://doi.org/10.18601/01236458.n56.03 


\section{ABSTRACT}

This article studies the Third-Party Funding in international arbitration (best known as TPF), in order to understand how TPF trends can promote its own development over the next ten years. Thus, once having examined the concept and evolution of the figure through a bibliographic review, the document analyzes the future of the TPF based on three of its most relevant trends: I) the exponential growth in the use of the figure, II) the arrival of the figure to markets where it was shallow or not at all known, and III) its recent stage of regulation. This paper concludes the next ten years of the TPF will likely be defined by its steady grow th because there are no signs of stagnation in its use and consolidation on new markets. Nevertheless, the future of the figure seems to be mainly linked to its legal regulation, since it would achieve a universal concept, as well as guarantee the validity of the figure in jurisdictions where it is currently prohibited, and contribute to solving criticisms against it.

Keywords: Third-party funding, third-party funder, funding agreement, arbitration, international arbitration, international commercial arbitration, investment arbitration, regulation.

\section{INTRODUCCIÓN}

Costoso, esa sería la palabra que puede venir a la cabeza de muchos abogados, inversionistas y comerciantes cuando piensan en el arbitraje como método para resolver las disputas, lo que se agrava aún más si se habla de un procedimiento arbitral de carácter internacional. De hecho, la International Arbitration Survey (una prestigiosa encuesta sobre arbitraje internacional que organiza la Escuela de Arbitraje Internacional del Queen Mary University of London [QMUL]) encontró en su edición del 2015 y 2018 que, según la perspectiva de practicantes, árbitros, académicos y otros grupos relacionados con el arbitraje internacional, los costos resultan ser la peor característica de este mecanismo de resolución de conflictos (QMUL y White \& Case, 2015, p. 7; QMUL y White \& Case, 2018, p. 8). La verdad es que esa caracterización negativa no es para menos, pues tiene fundamentos serios y sólidos para convertirse en una crítica legítima del arbitraje internacional, por ejemplo, las cifras de cuánto puede gastar una parte en un procedimiento arbitral adelantado ante el Centro Internacional de Arreglo de Diferencias Relativas a Inversiones (CIADI), se ubican — en promedio para el 2015- entre los 5.6 y 4.9 millones de dólares americanos (Commission, 2016).

En realidad, la cuestión de los altos costos persigue al arbitraje internacional —bien sea de tipo comercial o de inversiones- desde hace mucho tiempo, al punto tal de que ya es un aspecto amplio y fuertemente denunciado por un sector relevante de la doctrina (Najar, 2013, pp. 305-314; Abdel Wahab, 2019, pp. 465 y ss.; Franck, 2019, 
pp. 181-190; Lew, 2019, pp. 291 y ss.) ${ }^{2}$; sin embargo, que sea una problemática de antaño no implica que no existan alternativas o soluciones al respecto. Precisamente, este artículo se enfoca en una de ellas: el fenómeno de la financiación por terceros, mejor conocido como Third-Party Funding (en adelante TPF). En el arbitraje, el TPF es una figura que permite a una parte en disputa financiar los gastos de un procedimiento arbitral; básicamente, este fenómeno se compone por la oferta que brinda un tercero de financiar los costos que a una parte le signifique iniciar un arbitraje, ello a cambio de que el tercero (llamado financiador) reciba un beneficio económico sobre el derecho que potencialmente se pueda conseguir en el laudo que finalice la controversia o en un eventual arreglo de transacción (Cremades, 2012, p. 156; Osmanoglu, 2015, p. 326; Dos Santos, 2017, p. 918; Henriques, 2019, p. 170) $)^{3}$.

De tal manera, los usuarios del arbitraje internacional que no tienen la suficiente capacidad económica para hacerle frente, por ejemplo, a los altos costos de iniciar un arbitraje en una institución arbitral, a los honorarios de abogados, a los honorarios de los árbitros, al valor de los dictámenes periciales y demás gastos que requiera y genere el procedimiento arbitral, tendrán una posibilidad real de afrontarlos a través del TPF. Es más, podríamos decir que el financiamiento de terceros no solo es una herramienta para actores insolventes, pues tal y como lo afirma un tribunal arbitral de la Corte Permanente de Arbitraje ("CPA") en el caso Manuel García Armas y otros vs. La República Bolivariana de Venezuela del 2018:

la existencia de financiamiento por terceros no constituye per se prueba de la insolvencia de aquellos que recurren a dicho financiamiento. Ello porque, como remarcan los Demandantes, los motivos por los cuales se recurre a financiamiento por terceros pueden ser

2 Por ejemplo, para el 2011, las partes en un arbitraje internacional podían gastar en el procedimiento arbitral cifras entre $£ 1413000$ y $£ 1580000$ : (The Chartered Institute of Arbitrators [CIArb], 2011). Igualmente, Marquais y Grec (2020) detallan de una manera más actual que: "[...] el arbitraje internacional no necesariamente implica procedimientos más económicos. Por una cantidad en litigio de diez millones de dólares, los costos de un arbitraje en la Cámara de Comercio Internacional ("CCI") en el que participan tres árbitros se acercan a los 400000 dólares, pero éstos son solo la punta del iceberg. Los honorarios de los abogados y expertos, así como los gastos previstos de los testigos y otros gastos externos, representan, de lejos, la mayor parte de los costos incurridos en los procedimientos de arbitraje [...] En total, según la experiencia de los autores, los costos de un demandante superan con frecuencia el $10 \%$ de las cantidades de sus demandas" (traducción libre) (p. 50).

3 Esta es la vertiente más consolidada y conocida del TPF en el arbitraje internacional (Stoyanov y Owczarek, 2015, p. 172), comúnmente denominada como "financiación sin recurso con reembolso condicionado al éxito" (Bench Nieuwveld y Shannon Sahani, 2017, p. 7). No obstante, existen variantes de esta modalidad, tales como la financiación para portafolios de casos (donde se financian múltiples arbitrajes, lo que puede ser ofrecido tanto al cliente como a un bufete de abogados); financiar otros casos en lugar de la reclamación subyacente (así se garantiza el financiamiento con otras reclamaciones que tengan mejores probabilidades de éxito), descontar el pago de un laudo no cobrado; entre otros (Bogart, 2017, p. 319). Para un análisis detallado de las variantes del TPF véase a Von Goeler (2016, pp. 51 y ss.), Bench Nieuwveld y Shannon Sahani (2017, pp. 3 y ss.) y a Baumann y Singh (2018, pp. 32 y ss.). 
muy variados, incluyendo simples decisiones comerciales, mayor distribución de riesgos, razones de flujo de caja y otro tipo de motivos que nada tienen que ver con la insolvencia. ${ }^{4}$

Ahora, a pesar de ser una figura tan prometedora y beneficiosa, el TPF ha causado todo un revuelo en la comunidad arbitral confrontando a muchos a favor o en contra de él, ya que cierto sector pregona que es una forma de materializar el acceso a la justicia sin distinción de los factores económicos, y otro, por el contrario, le considera un riesgo a la integridad del procedimiento arbitral. Así, no sobran las posturas o visiones negativas sobre el $\mathrm{TPF}^{5}$; las cuales manifiestan que este fenómeno puede generar conflictos de interés en los árbitros, da pie a prácticas abusivas, incentiva la presentación de demandas frívolas, entre otras tantas críticas que abordaremos más adelante. Pero, a pesar de ello, lo cierto es que el TPF crece de manera exponencial y ya es toda una realidad para el arbitraje internacional de nuestros tiempos (Cremades Sanz Pastor, 2013, p. 153; Clanchy, 2016, p. 222; Mazzoni, 2019, p. 299; Fuchs y Richman, 2020, p. 73); además, bien valdría citar las reflexiones de un tribunal arbitral del CiADI en el caso Giovanni Alemanni y otros vs. República de Argentina del 2014, en el cual se sostuvo que:

Las opiniones individuales pueden diferir en cuanto a si la financiación de terceros resulta conveniente o beneficiosa o no, ya sea a nivel nacional como internacional, pero, a esta altura, la práctica está tan bien establecida tanto dentro de muchas jurisdicciones nacionales como dentro del arbitraje de inversión internacional que no ofrece fundamento alguno en sí misma para la objeción a la admisibilidad de una solicitud de arbitraje. ${ }^{6}$

Justamente, somos conscientes de esta nueva realidad y por ello nos encargaremos de estudiar el TPF de cara al futuro, específicamente en relación con lo que podría vivir esta figura en el ámbito del arbitraje comercial internacional y de inversiones por los próximos diez años (2020-2030). Esperamos no ser malinterpretados, ya que nuestro análisis no pretende predecir o vaticinar lo que será el TPF en los tiempos venideros; sino más bien examinar cómo se ha ido desarrollando la figura y qué tendencias están afrontando actualmente para así poder determinar el impacto que puedan tener esas

4 Véase Corte Permanente de Arbitraje (20 de junio de 2018) Manuel García Armas et al. vs. La República Bolivariana de Venezuela, Caso CPA n. ${ }^{\circ}$ 2016-08, 2018, p. 70. https://www.italaw.com/sites/ default/files/case-documents/italaw9849_2.pdf

5 Respecto a esta visión negativa, resulta anecdótica la situación ocurrida en el caso Teinver S.A et al. vs. La República de Argentina, donde los representantes legales de la Argentina calificaron a los abogados de la parte demandante y al tercero financiador como "un comité de buitres y cuervos": Centro Internacional de Arreglo de Diferencias Relativas a Inversiones (8 de abril de 2016) Teinver S. A. et al. vs. La República de Argentina, Caso CIADI n. ${ }^{\circ}$ ARB/09/1, p. 29. http://icsidfiles.worldbank. org/icsid/ICSIDBLOBS/OnlineAwards/C520/DC7892_Sp.pdf

6 Véase Centro Internacional de Arreglo de Diferencias Relativas a Inversiones (17 de noviembre de 2014) Giovanni Alemanni y otros vs. La República de Argentina, Caso CIADI n. ${ }^{\circ}$ ARB/07/8, p. 139. http://icsidfiles.worldbank.org/icsid/ICSIDBLOBS/OnlineAwards/C100/DC5132_Sp.pdf 
tendencias en el futuro de la figura y, sobre todo, cómo estas pueden ser usadas en pro del desarrollo mismo del TPF. Así, con este artículo pretendemos responder a la siguiente pregunta: ¿de qué forma las tendencias que atraviesa actualmente el TPF en el arbitraje internacional pueden favorecer su desarrollo en los próximos diez años (2020-2030)?

Para tales efectos, haremos primariamente un acercamiento conceptual a la figura del TPF, ello con el ánimo de entender su naturaleza y su funcionamiento en el marco del arbitraje internacional. Después, examinaremos el desarrollo y la evolución de la figura, lo que lograremos: A) analizando sus antecedentes; B) estudiando las posturas a favor o en contra de este fenómeno; C) e identificando las principales tendencias que afronta en la actualidad, dedicando especial énfasis a la más importante de todas: su reciente etapa de regulación de los últimos diez años en legislaciones domésticas, autorregulaciones de asociaciones de abogados y de financistas, reglas de instituciones arbitrales y normas de soft law. Finalmente, teniendo ese panorama de regulaciones como base, expondremos cómo esta tendencia puede apoyar el desarrollo del TPF, al igual que detallaremos las soluciones que pueden dar esas regulaciones a las críticas más fuertes que se han hecho a la financiación de terceros.

\section{LA NATURALEZA DEL TPF Y SU FUNCIONAMIENTO EN EL ARBITRAJE INTERNACIONAL}

Para iniciar, quisiéramos focalizar la conceptualización del fenómeno del TPF en el arbitraje internacional a través de lo que la doctrina considera es su naturaleza: un negocio de inversión en el financiamiento de arbitrajes (Bowman, Hurford y Khouri, 2011, p. 3; Affaki, 2013, p. 11; Derains, 2013, p. 5; Livschitz, 2018, p. 2615; Burghetto, 2020, pp. 83-84) ${ }^{7}$. Desde la perspectiva doctrinal, el TPF se explica como la decisión de un financiador de invertir en un determinado procedimiento arbitral; es decir, el financista solventa los gastos que tenga una parte en un arbitraje, esperando que esta sea victoriosa en el laudo y su éxito le traiga un beneficio económico (Osmanoglu, 2015, p. 329 y 330; Frignati, 2016, p. 508; Lefèvre, Callens y Croisant, 2017, pp. 36 37). Al respecto, Mazzoni (2019) afirma que

en términos económicos, este tipo de financiación es esencialmente una inversión, la cual es realizada por un tercero que considera el arbitraje como una oportunidad de negocio. La inversión se basa en la evaluación independiente y propia del financiador de las posibilidades de éxito que tenga en el arbitraje una demanda específica presentada por el demandante a su propio nombre. Es de destacar que una característica esencial del acuerdo de financiación es que todo el riesgo de la inversión es asumido por el inversor/financiador a cambio del derecho a un rendimiento significativo en caso de éxito (traducción libre). (p. 300)

7 Incluso autores como Henriques (2017) llegan a considerar que "una inversión de financiación de un tercero es una inversión protegida según los tratados internacionales de protección de inversiones" (p. 101). 
De tal manera, los financiadores asumen un riesgo en su inversión como lo haría cualquier financiador, ya que es perfectamente posible que la parte financiada pierda el caso y, con ello, que también se pierda el dinero invertido (Hashu, 2016, p. 79; Mereminskaya, 2017, p. 3; Barrington, 2017, p. 15). Con esto en mente, podemos afirmar que el riesgo asociado a financiar un arbitraje deriva, principalmente, de si la decisión arbitral es o no favorable a la parte financiada, pues de ello dependerá el éxito económico de la inversión del financiador (Frignati, 2016, pp. 508-509; Dos Santos, 2017, p. 919; Henriques, 2019, p. 170). Ahora, debe destacarse que ese riesgo asociado al TPF es muchísimo más elevado en comparación a otro tipo de financiamientos comerciales, ya que es difícil evaluar el resultado del caso, no se conoce con total claridad la fecha en la que terminará el arbitraje y, además, no hay pagos intermedios que el financiador pueda cobrar por financiar los costos del procedimiento arbitral (Cremades, 2012, p. 157; Von Goeler, 2016, pp. 75-80).

Por consiguiente, y teniendo en cuenta que "el objetivo básico de casi todos los inversionistas es obtener el rendimiento más alto con el menor riesgo" (Gitman y Joehnk, 2009, p. 44), resulta lógico que los financiadores se valgan de un sistema de gestión del riesgo bastante exigente para hacer de su inversión un negocio rentable. Precisamente, los financiadores buscan ese balance a través de un estudio detallado de los peligros y las virtudes de una disputa arbitral; así, por medio de ese examen pueden determinar si un arbitraje tiene realmente una base sólida y es digno de ser financiado (Cremades, 2012, p. 167; Navarro, 2014, p. 803; Frignati, 2016, p. 509; Von Goeler, 2016, pp. 13-28; Burghetto, 2020, p. 100). Ese estudio generalmente se llevará a cabo a través de un proceso de due diligence (o debida diligencia), por el que los financiadores hacen un análisis cauteloso de los hechos y los méritos de la disputa que buscan financiar (Cremades, 2012, pp. 166-167; Matray y Van Rompaey, 2017, p. 193; Lefèvre, Callens y Croisant, 2017, p. 37). Este proceso de debida diligencia es muy exhaustivo, pues tal y como detalla Frignati (2016):

Los factores clave que se analizan generalmente son los siguientes: i) el valor de la demanda $_{i}$ ii) la jurisdicción en la que se va a conocer la demanda y en la que se reconocerá y ejecutará el laudo; iii) la probabilidad de llegar a un acuerdo o ganar el arbitraje; iv) la calidad del equipo jurídico del litigante; v) la naturaleza y la duración prevista de las actuaciones arbitrales; vi) la práctica y la reputación de la institución arbitral ${ }_{i}$ vii) el derecho sustantivo de la controversia; viii) la calidad y la cantidad de las pruebas documentales, así como de las pruebas testimoniales; ix) la situación financiera de la contraparte y su capacidad de pago; y x) el fundamento jurídico de la demanda y los riesgos asociados a cualquier posible reconvención (traducción libre). (p. 509)

Así mismo, este examen de fondo es un proceso amplio en el que participan: I) los abogados que representan la parte a financiar en la disputa arbitral, puesto que ellos brindan la información a examinar, tales como su estrategia de litigio, las pruebas que pretenden aportar los fundamentos fácticos y jurídicos en los que basarán sus 
argumentos, etc.; II) los abogados internos de la entidad o persona que funge como financiador, los cuales valorarán — sustantiva y procedimentalmente- los riesgos y las posibilidades de éxito del arbitraje en cuestión; III) los peritos o mesas de expertos multidisciplinarias que aportarán su conocimiento en relación con las pruebas, la tasación de los daños, los asuntos técnicos de la disputa y demás situaciones en los que fuesen requeridos; IV) y en el marco de una última fase dentro de la due diligence también es frecuente que participen abogados que prestan asesoramiento legal externo, ello en función de dar una doble valoración del caso que se pretende financiar (Clanchy, 2016, pp. 230-231; Von Goeler, 2016, pp. 13-28; Bench Nieuwveld y Shannon Sahani, 2017, pp. 38-42; Burghetto, 2020, pp. 88-91).

Una vez culminado el proceso de diligencia y se llegue a la conclusión de que el caso es apto para ser financiado, se inicia la etapa de negociación y redacción del acuerdo de financiamiento. Este acuerdo se redacta determinando las condiciones particulares que cada caso requiera, ya que no existe un formato único respecto de los términos que deban pactarse en un acuerdo de financiamiento (Osmanoglu, 2015, p. 327; Livschitz, 2018, p. 2016); sin embargo, este tiende a contener algunas cuestiones ya estandarizadas en la práctica, tales como

i) la cantidad máxima que el financiador contribuirá a la representación jurídica del caso; ii) la indemnización que el financiador recibirá en caso de éxito (que varía entre el 15 y el $50 \%$ de la cantidad adjudicada); iii) los costos que el financiador asumirá si se pierde el caso (por ejemplo, los costos de la ejecución del laudo, los costos adversos y los honorarios jurídicos de la parte ganadora). Un acuerdo de financiación redactado con prudencia incluirá también: i) una disposición que regule el grado de influencia y control que un financiador puede ejercer en el procedimiento arbitral y en la estrategia procesal en general (por ejemplo, en la decisión de resolver la controversia) ii) un método para resolver cualquier desacuerdo que pueda surgir entre el financiador y la parte financiada; iii) las causas por las que se puede poner fin a la relación; y iv) una cláusula de confidencialidad para proteger la información de la que el financiador tenga conocimiento durante el proceso de diligencia debida y a lo largo del procedimiento arbitral (traducción libre). (Frignati, 2016, p. 510) ${ }^{8}$

Como se puede apreciar, el proceso de debida diligencia para culminar un acuerdo de financiación es muy detallado, exigente y pormenorizado, ya que, si se considera que la decisión de invertir en un arbitraje depende de que exista un balance óptimo entre los riesgos de la disputa y las posibilidades serias de que esta rinda beneficios (Bench Nieuwveld y Shannon Sahani, 2017, p. 38), resulta evidente la necesidad de surtir ese proceso de diligencia y valerse del engranaje de personas y elementos a analizar que

8 Para una referencia más detallada de los elementos que se tienden a pactar en un acuerdo de financiación, véase a Von Goeler (2016, pp. 28 y ss.) y a Bench Nieuwveld y Shannon Sahani (2017, pp. 22 y ss.). 
este implica. Incluso, los financiadores no solo deberían quedarse con la due diligence; sino que, una vez iniciado el arbitraje, también deberían hacer un monitoreo activo de este para proteger y solidificar su inversión (Wheal y Brumpton, 2016; Dos Santos, 2017, p. 925; Matray y Van Rompaey, 2017, p. 183).

Por otro lado, es necesario indicar que la materialización de un acuerdo de financiamiento no es una cuestión sencilla del todo; de hecho, un estudio de la International Chamber of Commerce en Francia y algunas valoraciones anecdóticas o investigaciones independientes, sugieren que solo entre el $5 \%$ y el $10 \%$ de los casos sujetos al análisis de los terceros financiadores son realmente aceptados para ser financiados (Hendel, 2010, p. 77, Veljanovski, 2012, pp. 420 y 436; Villa, 2014, p. 209; Von Goeler, 2016, p. 25). Además, los financiadores de terceros generalmente solo financian disputas que tengan entre un $60 \%$ y $75 \%$ de probabilidades de ser exitosos, así como tienden a no financiar controversias con pretensiones avaluadas con un bajo valor en términos económicos (Veljanovski, 2012, p. 425; Scherer, Goldsmith y Flechet, 2012, p. 213; Seidel, 2013, p. 25; Von Goeler, 2016, p. 25).

\section{DESARROLLO DEL FINANCIAMIENTO DE TERCEROS \\ EN EL ARBITRAJE INTERNACIONAL}

\section{Antecedentes del TPF}

A grandes rasgos acabamos de definir qué es el TPF desde una perspectiva doctrinal y cómo se manifiesta en el marco del arbitraje internacional, bien sea en el ámbito del arbitraje de inversiones o en el campo del arbitraje comercial internacional. Ahora, adentrándonos a los antecedentes de la figura, vale destacar que el financiamiento de terceros tiene una larga tradición de ser prohibido en los sistemas jurídicos influenciados por el common law. La verdad es que el TPF no nace con el arbitraje internacional, de hecho, tanto en el arbitraje de inversiones como en el del tipo comercial internacional es un fenómeno relativamente reciente y en auge (Park y Rogers, 2015, pp. 115 y 121; Shaw, 2017, pp. 109 y 120; Matray y Van Rompaey, 2017, p. 194; Güven, Lockhart y Garcia, 2020, pp. 287-288). El TPF tiene sus antecedentes en el campo del litigio ante las cortes nacionales de países afiliados al common law principalmente (Kalajdzic, Cashman y Longmoore 2013, pp. 93 y ss.; Osmanoglu, 2015, p. 328, Solas, 2019, p. 39), remontado sus raíces más antiguas a ciertas prácticas realizadas durante la Antigua Grecia y Roma que posteriormente se consolidaron con mayor fuerza durante la Edad Media en Inglaterra (Goldsmith y Melchionda, 2012, pp. 54-55; Osmanoglu, 2015, p. 328; Solas, 2019, pp. 17 y ss.).

En la misma Edad Media, el financiamiento de terceros empezó a concebirse como una práctica indeseable ante las cortes judiciales de afiliación con el derecho anglosajón, constituyéndose como un arreglo ilegal que, inclusive, fue una ofensa de tipo criminal por muchos años en Inglaterra (Lord Neuberger, 2013, pp. 6-19; Hou, 2018, pp. 599-600; Solas, 2019, pp. 17 y ss.). Así, durante ese periodo dicha práctica fue 
prohibida por el common law bajo tres teorías denominadas como Barretry, Maintenance y Champerty (Lord Neuberger, 2013, pp. 5-10; Bench Nieuwveld y Shannon Sahani, 2017, p. 15; Solas, 2019, pp. 24 y ss.), las cuales consideraban el hecho de apoyar o promover económicamente el litigio de otro como una conducta poco ética (Frignati, 2016, p. 505; Ramesh, 2020, p. 276). En particular, la teoría del Maintenance consiste en recibir apoyo financiero, de manera directa o indirecta, de otra persona para iniciar o defenderse en un procedimiento judicial que no tiene mayor fundamento legal ${ }_{i}$ a su vez, las teorías del Barretry y Champerty, se refieren a unas formas agravadas del Maintenance, donde las personas que financiaban un litigio lo hacían de manera más regular y esperando recibir algún beneficio económico (Lord Neuberger, 2013, p. 5; Osmanoglu, 2015, p. 328; Bench Nieuwveld y Shannon Sahani, 2017, p. 44; Ramesh, 2020, p. 276).

Dichas teorías o doctrinas, las cuales se tornaban como un asunto de protección al orden público (Stoyanov y Owczarek, 2015, p. 174; Bench Nieuwveld y Shannon Sahani, 2017, p. 14, Ramesh, 2020, p. 276), tenían como fin evitar los efectos negativos que se pueden producir por ver en la justicia una fuente de negocios y riqueza. Estos efectos negativos podían ir desde aumentar el número de demandas frívolas o sin fundamento serio para demandar, litigios injustificados solo con el ánimo de recibir ganancias y en pos de un lucro personal para el financiador (Steinitzt, 2011, p. 1327; Stoyanov y Owczarek, 2015, p. 174) o, en palabras de la Corte de Apelaciones de Inglaterra y Gales en el caso Re Trepca Mines Ltd del año 1962: "el common law teme que el champertous maintainer se vea tentado, para su propio beneficio, a inflamar los daños, a suprimir las pruebas o, incluso, a sobornar a los testigos" (traducción libre) ${ }^{9}$. Como se puede apreciar, las prohibiciones recogidas en las doctrinas del Barretry, Maintenance y Champerty tienen una clara vocación de proteger a la justicia de factores económicos externos, pues bien detallan Stoyanov y Owczarek (2015), que "al convertir el litigio en una industria, la preocupación era que la financiación de terceros alentaría un comportamiento imprudente y amoral" (traducción libre) (p. 175).

No obstante, poco a poco el enfoque prohibitivo de estas doctrinas ha ido desmontándose, a tal punto que dejaron de ser delitos en Inglaterra desde 1967; así mismo, el financiamiento de terceros ha ido aceptándose paulatinamente en algunos procedimientos judiciales de esta y otras jurisdicciones, como Australia (Lord Neuberger, 2013, pp. 6-19; Stoyanov y Owczarek, 2015, pp. 174-181; Osmanoglu, 2015, p. 328; Dos santos, 2017, p. 931). Sin embargo, la influencia de las doctrinas del Barretry, Maintenance y Champerty ha sido notable para negar el TPF en otras jurisdicciones que adoptan el common law y que aún no han permitido expresamente la práctica, por ejemplo, en el 2017, la Suprema Corte de Justicia de Irlanda, en el caso Persona Digital Telephony Ltd and another vs. The Minister for Public Enterprise, Ireland and

9 Véase Corte de Apelaciones de Inglaterra y Gales (30 de julio de 1962) Re Trepca Mines Ltd., [1963] Ch. 199. https://uk.practicallaw.thomsonreuters.com/D-017-1855?transitionType=Default\&contex tData $=($ sc. Default $) \&$ firstPage $=$ true 
Others, consideró que el financiamiento de terceros aún estaba prohibido por virtud de las mencionadas doctrinas ${ }^{10}$. Igual situación ocurre en países como Malasia (Bench Nieuwveld y Shannon Sahani, 2017, p. 250; Nathan et al., 2020) y hasta hace poco fue así en jurisdicciones como Hong Kong y Singapur, quienes solo permitieron el uso del TPF hasta el 2017, por medio de reformas legales que se detallan más adelante (Bajaj, Yang y Chan, 2020).

\section{Los aspectos negativos y positivos del TPF}

\section{Las críticas al financiamiento de terceros}

Con unos antecedentes tan marcados, es normal que el financiamiento de terceros genere toda una serie de dudas y recelos; es más, el sector de la doctrina que actualmente detalla los peligros del TPF en el arbitraje internacional mantiene vigentes ciertas preocupaciones desarrolladas a la luz de las doctrinas del Barretry, Maintenance y Champerty. Particularmente, sobresalen las preocupaciones de que el TPF puede significar un aumento en el número de demandas frívolas y sin fundamentos jurídicos serios para demandar, así como la crítica de que los financiadores pueden actuar de una manera poco ética y profesional. Respecto a la cuestión de las demandas frívolas, cierto sector de la doctrina considera que el TPF puede incentivar la presentación de demandas "exageradas" o "especulativas", las cuales no habrían sido presentadas de no haber existido una financiación de por medio (Garino Podestá y Picardo González, 2019, p. 46). Tan latente es esta preocupación que en el 2013 la United Nations Conference on Trade and Development ("UNCTAD") afirmaba — en materia de arbitrajes entre inversionistas y Estados- que

existen serias razones de política contra el TPF en las reclamaciones sobre acuerdos internacionales de inversión; por ejemplo, este puede aumentar la presentación de reclamaciones dudosas. Desde la perspectiva del Estado demandado, esas reclamaciones frívolas, incluso si la mayoría de ellas fracasan, pueden consumir recursos importantes y causar daños a la reputación (traducción libre). (p. 25)

Sin embargo, la doctrina mayoritaria se ha encargado de criticar la versión de que el TPF alienta la presentación de demandas especulativas, puesto que el uso del TPF pareciera generar el efecto totalmente contrario, ya que los financiadores solo tienden a invertir en casos que parecen ser realmente robustos y seguros (Steinitzt, 2011, p. 1327; Frignati, 2016, p. 509; Lefevre, Callens y Croisant, 2017, pp. 41-42; Shaw, 2017, p. 112). Al respecto, Dos Santos (2017) explica que "es más probable que los financiadores

10 Véase Suprema Corte de Justicia de Irlanda (23 de mayo de 2017) Persona Digital Telephony Ltd and another $v$ s. The Minister for Public Enterprise, Ireland and Others, [2017] IESC 27, 2017. https:// www.bailii.org/ie/cases/IESC/2017/S27.html 
actúen como guardianes, filtrando reclamaciones frívolas en lugar de alentarlas" (traducción libre) (p. 926). En efecto, nosotros estamos de acuerdo con esta posición, pues los financiadores de terceros someten sus casos a procesos de due diligence muy exigentes como lo relatamos párrafos atrás, por lo que parece contradictorio asumir que el TPF alienta la presentación de demandas frívolas. Igualmente, debe recordarse que los financiadores deben su éxito al resultado de las disputas, razón por la que no financian cualquier caso, sino únicamente los que ofrecen oportunidades serias de rendir beneficios (Lamm y Hellbeck, 2013, p. 106; Hashu, 2016, pp. 87-88) ${ }^{11}$.

No obstante, esta idea que defendemos solo tendría efecto respecto a la manifestación del TPF más consolidada actualmente, que es precisamente la que presentamos en este artículo ${ }^{12}$; empero, recientemente han aparecido ciertas variantes del TPF que sí podrían fomentar la presentación de demandas especulativas. Así, por ejemplo, existe la financiación para portafolios de casos, donde el financiador ofrece a una firma de abogados o a un cliente la opción de financiar múltiples arbitrajes al mismo tiempo, por lo que habrá mayores probabilidades de que por lo menos uno de esos casos genere ganancias; o la financiación de otros arbitrajes en lugar de la reclamación subyacente, de manera tal que se garantiza el financiamiento con otras reclamaciones que tengan mejores probabilidades de éxito que la disputa a financiar (Bogart, 2017, p. 319; Baumann y Singh, 2018, pp. 32-43). Todas estas variantes del TPF implican menores niveles de riesgo para los financiadores de terceros (Bogart, 2017, pp. 319-320; Bench Nieuwveld y Shannon Sahani, 2017, pp. 4-7; Baumann y Singh 2018, pp. 32-43), motivo por el que estos podrían estar dispuestos a financiar casos no meritorios (Bench Nieuwveld y Shannon Sahani, 2017, p. 68; Brown de Vejar y Baldwin, 2019, pp. 541-548); por lo tanto, la aparición de estas variantes mantiene vigente -al menos en cierto sentido- la crítica de que el TPF alienta la presentación de demandas especulativas (Mereminskaya, 2017, p. 5; Darwazeh y Leleu, 2016, pp. 129-130).

Ahora, si bien defendemos que en su manifestación más conocida el TPF no alienta las demandas frívolas, también debemos reconocer que no sobran los casos que, aunque aislados, sirven de fundamento para que algún sector justifique la crítica que estamos analizando. Esa es la condición del caso Excalibur Ventures vs. Texas Keystone and Others, fallado por la Corte de Apelaciones de Inglaterra y Gales en el 2016 ${ }^{[13]}$. Es de anotar que si bien este caso no se refiere al TPF en el arbitraje internacional, su problemática podría verse reflejada en cualquier procedimiento arbitral de esta

11 Sobre una visión más detalla de la postura de que el TPF no alienta a la presentación de demandas especulativas o frívolas, así como a su verificación en data empírica. Véase a Popova y Seifert (2020, pp. 135 y ss.).

12 Véase la nota al pie 3.

13 Véase Corte de Apelaciones de Inglaterra y Gales (18 de noviembre de 2016) Excalibur Ventures vs. Texas Keystone and Others [2016] EWCA Civ 1144. Disponible en: https://www.bailii.org/ew/cases/ EWCA/Civ/2016/1144.html 
naturaleza ${ }^{14}$. En este, la demandante, que era una empresa fantasma solventada en la parte económica por un grupo de varios financiadores (Stoyanov y Owczarek, 2015, p. 177; Von Goeler, 2016, p. 94; Wheal y Brumpton, 2016), alegó tener un 30 \% en la participación de un campo petrolífero de las demandadas, motivo por el cual exigía la cantidad de 1600 millones de dólares americanos (Von Goeler, 2016, p. 94).

Tanto en primera instancia como en sede de apelación, se encontró que la demanda era especulativa, ya que se había fundamentado en argumentos oportunistas, declaraciones falsas y en alegaciones elaboradas artificialmente; así como también se identificó que la reclamación económica solicitada era muy exagerada (Von Goeler, 2016, p. 94; Wheal y Brumpton, 2016; Matray y Van Rompaey, 2017, p. 183). Finalmente, los financiadores fueron condenados al pago de las costas de ese procedimiento, pues el tribunal entendió que "la naturaleza derivada de la participación de un financiador comercial debería llevar a que se le exija que contribuya con los costos" (traducción libre), máxime cuando el financiador no puede "disociarse de la conducta de aquellos a quienes ha permitido llevar a cabo el litigio y en quienes confía para obtener un retorno de su inversión" (traducción libre) (Corte de Apelaciones de Inglaterra y Gales, 18 de noviembre de 2016). Como se puede evidenciar, este caso es un claro ejemplo de que un tercero financiador, en efecto, sí puede llegar a solventar demandas frívolas y especulativas.

Naturalmente, con la cuestión de las demandas frívolas también aparecen las críticas relativas a que los terceros financiadores pueden actuar de manera poco ética y profesional. Estas críticas pueden ser justificadas por muchos a la luz del caso Excalibur, ya que esta demuestra qué es lo que puede suceder cuando un financiador no tiene unos estándares éticos y profesionales adecuados para definir qué caso financiará. Además, esta decisión también refleja en sí mismo un estándar profesional que deberían acoger los financiadores de terceros, pues la misma confirma que es necesario que estos ejerzan un control adecuado sobre el caso que están financiando, no solo realizando una due diligence robusta o sólida, sino también mediante un monitoreo activo del caso cuando este ya ha empezado a tramitarse (Wheal y Brumpton, 2016; Dos Santos, 2017, p. 925; Clanchy, 2017).

Igualmente, en el arbitraje internacional también se ha identificado otra práctica constitutiva de un actuar poco ético y profesional por parte de los financiadores: el denominado arbitraje "bit-and-run". Esta práctica es explicada por Garino Podestá y Picardo González (2019) de la siguiente manera:

Se conoce como arbitrajes "bit-and-run" a aquellos en los cuales la parte demandante insolvente — valiéndose de TPF— no tiene éxito en la disputa, pero ni la demandante

14 Este caso no sirve como un referente para que un tribunal arbitral condene en costas a un financiador, ya que estos no son parte en un arbitraje (Pizarro, 2017, pp. 239 y 240); por consiguiente, un tribunal arbitral no tiene "poderes discrecionales para responsabilizar a terceros por los costos" (traducción libre) (Dos Santos, 2017, p. 925). 
ni el tercero financiador se hacen cargo de una condena adversa en costos. El "bit-andrun" requiere que el tercero no haya asumido la responsabilidad por estos costos en el acuerdo de financiamiento respectivo. La demandada no puede ejecutar el laudo contra la demandante — que no tiene fondos o bienes propios - ni contra el financiador que no es parte del arbitraje. (p. 46)

Evidentemente, el arbitraje bit-and-run entraña serios dilemas éticos para el arbitraje internacional, ya que el financiador se ve beneficiado en todos los escenarios hipotéticos en los que puede terminar una disputa de esta naturaleza. Así, en caso tal de que el financiado resulte exitoso en el procedimiento arbitral, el financiador recibirá el retorno de su inversión y, por el contrario, si el financiado pierde y es condenado en costas, el tercero financista no responderá, porque no es parte en el arbitraje ni se ha responsabilizado a asumir los costos en el acuerdo de financiación (Darwazeh y Leleu, 2016, p. 131; Brekoulakis y Von Goeler, 2017, p. 12; Kamnani y Kaushal, 2019, p. 160).

En otro aspecto, debemos indicar que no todas las críticas contra el TPF acogen las preocupaciones desarrolladas a la luz de las doctrinas del common law del Barretry, Maintenance y Champerty, ya que en el arbitraje internacional se han generado algunas problemáticas propias de las cuales sobresalen que: I) el financiamiento de terceros puede dar lugar a conflictos de interés en los árbitros que fallen una disputa sujeta a financiamiento; y II) el TPF puede demostrar la insolvencia económica del financiado y, por tanto, hacer necesario órdenes de security for costs en el procedimiento arbitral. En relación con el primer problema, gran parte de la doctrina prevé una relación entre el financiamiento de terceros y los conflictos de interés en el arbitraje internacional; sin embargo, la academia no ha sido tan activa en identificar por qué surgen esos conflictos de imparcialidad en presencia del TPF (Camayo Ortiz, 2020, pp. 91-92), pues su interés principal ha sido exponer los supuestos en concreto en los que un árbitro tendría un conflicto de interés por esa razón y las posibles formas de prevenirlo (Osmanoglu, 2015, pp. 332-349, Stoyanov y Owczarek, 2015, pp. 186-191; Frignati, 2016, pp. 512 y ss.; Dos Santos, 2017, pp. 923 y ss.).

No obstante, en otro texto nos hemos preguntado por la causa de que el TPF genere conflictos de interés, para lo cual sostenemos como tesis que esta figura propicia estos por las relaciones económico-materiales que genera dentro del procedimiento arbitral (Camayo Ortiz, 2020, pp. 93-94). Para profundizar nuestra postura, hemos de decir que esta nace del pensamiento del autor Jonas Von Goeler (2016), quien sostiene que "la financiación por terceros tiene indudablemente el potencial de crear relaciones económicas materiales que la otra parte debería tener derecho a conocer y a impugnar" (traducción libre) (p. 254). Desde nuestra perspectiva, estas relaciones económicas se compaginan con la idea de que el TPF es un negocio de inversión como identificamos párrafos atrás, lo que convierte al financiador en un inversionista preocupado por hacer de su negocio una cuestión rentable y exitosa; siendo así, el financiador evitará en la mayor medida posible los riesgos de financiar un arbitraje, los que se derivan principalmente de si la decisión arbitral es o no favorable a la parte financiada. 
Por lo tanto, tener a un agente extraño al proceso arbitral que funda su negocio en prever si las decisiones arbitrales son favorables al consumidor de su financiamiento, ocasiona un ambiente preciso para que se presenten múltiples supuestos de conflictos de interés, ya que los financiadores buscarán disminuir los riesgos de su inversión previendo la decisión arbitral o directamente controlándola (Camayo Ortiz, 2020 , p. 94). Respecto al primer tipo de conflictos de interés - es decir, cuando los financiadores prevén la decisión de los árbitros- estos se dan como consecuencia de la manera en la que operan los financiadores de terceros; ya que, como se sostuvo párrafos atrás, los financiadores hacen un proceso de due diligence en el que participan multiplicidad de actores internos o externos, donde es posible que esté inmiscuido una persona o entidad que tenga una relación cercana con quien vaya a ser el árbitro en un determinado arbitraje, relación que por supuesto puede llegar a comprometer la imparcialidad de ese árbitro (Stoyanov y Owczarek, 2015, p. 187; Camayo Ortiz, 2020,94-96). Cabe anotar que este tipo de relaciones cercanas podrían no ser poco frecuentes o aisladas, ya que la doctrina ha identificado que la industria de la financiación de terceros está muy concentrada y, además, existe una relación simbiótica entre algunas de estas entidades financistas y prestigiosas firmas de abogados que se dedican al arbitraje internacional (Park y Rogers, 2015, p. 119; Garino Podestá y Picardo González, 2019, p. 47).

En relación con el segundo tipo de conflictos - es decir, donde los terceros financiadores directamente intentan controlar la decisión arbitral_, estos resultan los supuestos más indeseables que se pueden dar de acuerdo con un conflicto de imparcialidad ocasionado por el TPF, ya que se parte de la idea de que el árbitro tiene sus intereses directamente comprometidos con el tercero financiador (Camayo Ortiz, 2020, p. 97). Por ejemplo, Frignati (2016) detalla de la siguiente manera dos escenarios en los cuales los árbitros tienen sus intereses directamente comprometidos con el financiador de terceros: "el fenómeno del financiamiento de terceros puede causar un conflicto de interés con un árbitro designado cuando: (i) el árbitro posee acciones en una corporación de financiación de terceros, [...] o (iii) El mismo financiador externo indirectamente ha hecho múltiples designaciones" (traducción libre) (p. 515). Al igual que con el primer tipo de conflictos, este tipo de relaciones podrían no ser extrañas o imposibles, ya que algunos terceros financiadores promocionan sus servicios mostrando como miembros de sus entidades a reconocidos árbitros internacionales (Garino Podestá y Picardo González, 2019, p. 47).

Ahora, la doctrina ha considerado que todos estos posibles tipos de conflictos de interés pueden ser solucionados a través de un deber procesal de revelación, el cual implica que las partes comuniquen que están recibiendo financiación de un tercero y quién es ese tercero (Osmanoglu, 2015, pp. 339-349; Frignati, 2016, p. 516; Bench Nieuwveld y Shannon Sahani, 2017, p. 70; Theoduloz, 2019, p. 176; Popova y Seifert, 2020, pp. 144-150). De tal manera, si esa información se revela a la parte no financiada y a los árbitros, se pueden conocer las relaciones económico-materiales que ese financiamiento genera en un procedimiento arbitral y, así, también determinar si 
un árbitro tiene o no un conflicto de interés a causa un tercero financiador (Camayo Ortiz, 2020, p. 100) ${ }^{15}$. No obstante, algunos autores dudan de la existencia del deber en mención por no haber un fundamento legal de este hasta el momento; por ejemplo, Von Goeler (2016) afirma que

En la actualidad, las partes en un arbitraje internacional comercial o de inversiones no tienen la obligación procesal de revelar el hecho de que están siendo financiadas. Ninguna ley o reglamento de arbitraje exige actualmente a una parte que revele cómo financia su demanda o defensa. La obligación o práctica general de las partes financiadas de revelar las fuentes de sus fondos, por ejemplo, "como una cuestión de equidad", no está reconocida (traducción libre). (p. 126)

Por otro lado, en relación con la crítica de que el financiamiento de terceros puede demostrar la insolvencia económica de los financiados, y con ello, hacer necesarias órdenes de security for costs en el procedimiento arbitral; esta se debe a la finalidad que tiene el TPF de solventar los gastos que tenga una parte a raíz de un arbitraje. Como bien hemos indicado en la introducción a este artículo, el TPF intenta ser una alternativa para solventar los altos costos de un arbitraje internacional, por lo que parecería lógico que si una parte no tiene el dinero suficiente para iniciar un procedimiento de esta naturaleza, tampoco tenga el dinero para soportar las costas de la contraparte en caso de resultar vencida. Al respecto, Shaw (2017) sostiene que

Normalmente, un tribunal arbitral hará que la parte vencedora recupere sus costas de la parte perdedora. Sin embargo, una parte a menudo no sabe si su oponente puede permitirse un laudo de costes adversos. Por lo tanto, las partes solicitan cada vez más security for costs al comienzo del procedimiento. La presencia de un tercero financiador es un fuerte indicador de que la parte perdedora no podrá hacer frente a una indemnización por gastos adversos. De hecho, si una parte insolvente no puede sufragar los gastos de la tramitación de su demanda o defensa, y por consiguiente recurre a la asistencia de un tercero financiador, lo más probable es que no pueda sufragar los gastos de su oponente (traducción libre). (p. 115)

15 En relación con el impacto positivo que tiene este deber respecto a los árbitros, nosotros sostenemos que: "el aspecto más importante de este deber es que permite a los árbitros efectivamente conocer y comunicar a las partes hechos que puedan generar un conflicto de interés relacionado al TPF (ello de conformidad con el deber que tienen los árbitros de comunicar a las partes hechos que puedan afectar su imparcialidad). Lo anterior se explica en tanto ningún árbitro puede informar que tuvo una relación antigua con un financiador, que ese financiador recibió apoyo de su firma, que ha sido designado múltiples veces por un financiador o comunicar cualquier otro supuesto de un eventual conflicto de interés, si es que no conoce que el financiador está inmiscuido en el procedimiento arbitral que adelanta" (Camayo Ortiz, 2020, p. 100). 
De tal manera, en ese escenario de incertidumbre nacen las órdenes de security for costs como una aparente respuesta, pues a través de estas se obliga a la parte de la que se duda su solvencia económica a constituir una fianza, ello con el ánimo de garantizar que responderá sobre los costos del procedimiento arbitral de su contraparte en caso de resultar condenada a pagar tales costos (Garino Podestá y Picardo González, 2019, p. 51; Sim, 2017, p. 428; Karl, 2020, pp. 565-566). Esta figura, la cual encuentra resonancia en la cautio judicatum solvi del civil law (Kirtley y Wietrzykowsk, 2013, p. 19; Rosenfeld, 2016, p. 163), es frecuentemente usada en el campo del litigio del derecho anglosajón; sin embargo, se ha ido incorporando sustancialmente al arbitraje internacional (Fernández Masiá, 2016, p. 216). Así, esta se ha convertido en un asunto procesal recurrente en arbitrajes en los que exista TPF, ya que se ha empezado a considerar, como un argumento fuerte para solicitar una orden de security for costs, el hecho de que una parte que parezca carecer de recursos económicos presente una demanda de arbitraje a través de la financiación de un tercero (Born, 2014, p. 2496; Sim, 2017, p. 483; Brown de Vejar y Baldwin, 2019, pp. 529 y ss.).

No obstante, la práctica arbitral parece mantenerse dividida entre si un acuerdo de financiamiento en un arbitraje representa un argumento sólido para emitir una caución sobre las costas (Mereminskaya, 2017, p. 6), pues algunos entienden que la financiación no implica por sí sola la insolvencia económica del financiado (Sim, 2017, pp. 483-485; Garino Podestá y Picardo González, 2019, p. 56; Rueda-García, 2020, pp. 112-119; Popova y Seifert, 2020, pp. 141-144). Bien citamos en nuestra introducción el caso de la CPA de Manuel García Armas et al. vs. La República Bolivariana de Venezuela, donde claramente se sostiene que: "los motivos por los cuales se recurre a financiamiento por terceros pueden ser muy variados, incluyendo simples decisiones comerciales, mayor distribución de riesgos, razones de flujo de caja y otro tipo de motivos que nada tienen que ver con la insolvencia"16. En todo caso, resultan oportunas las reflexiones que hace un tribunal arbitral de la CPA en el caso South American Silver vs El Estado Plurinacional de Bolivia del año 2018, donde se manifiesta que:

La existencia de un tercero financiador por sí sola no prueba la imposibilidad de pago o la insolvencia [...] Si la existencia de esos terceros por sí sola, sin considerar otros factores, se vuelve determinante al conceder o rechazar una solicitud de security for costs, los demandados podrían solicitar y obtener la garantía de manera sistemática, lo que aumentaría el riesgo de bloquear reclamaciones potencialmente legítimas [...] En resumen, la existencia de un financiador es un elemento a tener en cuenta, pero los tribunales han sido claros en que la existencia del financiador por sí sola no es suficiente para la security for costs (traducción libre). ${ }^{17}$

16 Véase Corte Permanente de Arbitraje (20 de junio de 2018) Manuel García Armas et al. vs. La República Bolivariana de Venezuela, Caso CPA n. ${ }^{\circ}$ 2016-08, 2018, p. 70. https://www.italaw.com/sites/ default/files/case-documents/italaw9849_2.pdf

17 Véase Corte Permanente de Arbitraje (11 de junio de 2016) South American Silver vs El Estado 
Acceso a la justicia y otras virtudes del financiamiento de terceros

Afortunadamente el TPF no ha generado únicamente voces negativas, ya que implica una serie de ventajas y virtudes que abordaremos a continuación. Particularmente, se han identificado en el mundo académico tres grandes virtudes del TPF: I) garantiza el acceso a la justicia sin distinción de los factores económicos; II) nivela el "campo de juego" entre las partes; y III) permite a los actores que inician un arbitraje diversificar los riesgos económicos de un procedimiento de esta naturaleza. Respecto a la primera virtud, debe indicarse que el TPF es una herramienta que permite un margen de acceso a la justicia arbitral muchísimo más elevado (Frignati, 2016, p. 507; Von Goeler, 2016, pp. 82-88; Livschitz, 2018, pp. 2619-2620; Rueda-García, 2020, pp. 104-107), ya que esta figura evita que el factor económico sea una barrera para iniciar un arbitraje, por lo que las partes financiadas no se ven limitadas a presentar sus reclamaciones por los altos costos de este tipo de procedimientos (Derains, 2013, pp. 5-6; Dos Santos, 2017, pp. 920-921; Lefevre, Callens y Croisant, 2017, p. 37).

Debe recordarse que la noción de acceso a la justicia es una de esas características fundamentales de la solución de controversias, por lo que la financiación de terceros implicaría garantizar el disfrute efectivo de ese derecho si se evita que el único argumento para denegar dicho acceso sea la condición económica de una de las partes (Henriques, 2017, pp. 122-129). Ahora, el acceso a la justicia no puede ser considerado únicamente como la posibilidad de demandar y defenderse en un tribunal, sino también que la resolución de una disputa se haga de una manera pronta, oportuna y eficaz, así como que las partes sean tratadas de una manera justa y equitativa (Henriques, 2017, p. 122). En ese sentido, que exista una figura que permita solventar el pago de los honorarios de abogados, el costo de las pruebas que tengan que realizarse y demás gastos que sean necesarios en un procedimiento arbitral para que una disputa sea litigada de una manera correcta y adecuada, brinda a las partes financiadas la posibilidad de actuar en un arbitraje sin estar limitados por su condición económica; así, el financiamiento de terceros no solo garantiza el acceso a la justicia, sino también el equilibrio entre las partes de un arbitraje internacional.

Por lo tanto, el financiamiento de terceros nivela "el campo de juego" del procedimiento arbitral, ya que logra que las partes financiadas en un arbitraje internacional litiguen a la altura de sus oponentes quienes pueden ser más fuertes financieramente $\mathrm{y}$, por ende, disponen de mejores recursos para obtener decisiones favorables (Bogart, 2013, pp. 51-53; Von Goeler, 2016, pp. 87-88; Livschitz, 2018, pp. 2619-2620). De tal manera, el TPF permite que un arbitraje no sea una disputa entre "David y Goliat", sino entre partes que se pueden considerar a sí mismos como iguales (Dos Santos, 2017, p. 920), consiguiendo así que la controversia sea resuelta realmente sobre los argumentos expuestos en el procedimiento arbitral y no sobre la base de quien pudo

Plurinacional de Bolivia, Caso CPA n. ${ }^{\circ} 2013-15$, p. 12. https://www.italaw.com/sites/default/files/ case-documents/italaw7176.pdf 
gastar más o no en este (Von Goeler, 2016, p. 87). En particular, esta nivelación del campo de juego resulta muy evidente en los arbitrajes en materia de inversiones, ya que los Estados generalmente tienden a disponer de mejores recursos económicos para gastar en un arbitraje que los que podría permitirse cualquier inversionista (Frignati, 2016, p. 507; Yeoh, 2016, pp. 119 y ss.).

Además, el TPF — como ya lo hemos detallado ampliamente en párrafos anterioresno solo es una herramienta para actores insolventes; sino también para aquellos que desean diversificar los riesgos que implica iniciar un arbitraje o simplemente desean tener un mayor flujo de caja (Stoyanov y Owczarek, 2015, p. 172; Von Goeler, 2016, pp. 83-84; Matray y Van Rompaey, 2017, p. 194; Garino Podestá y Picardo González, 2019 , p. 42 $)^{18}$. Para una empresa o un inversionista, dedicar parte de sus activos líquidos a una controversia puede ser una decisión totalmente contraria a la perspectiva de su negocio, por lo que contar con un mecanismo que facilite solventar esos gastos y, además, permita que estos sean pagados del valor de una eventual condena contra la contraparte, implica liberar a estos agentes de una carga significativa. De tal modo, el TPF se convierte en una decisión estratégica para estos inversionistas o empresarios (Frignati, 2016, p. 518); inclusive, Livschitz (2018), hablando de este asunto desde la perspectiva de la financiación de terceros en Suiza, afirma que

También las entidades financieramente sólidas pueden considerar la posibilidad de utilizar la financiación de terceros para gestionar su presupuesto o para diversificar de manera más general el riesgo que conlleva cualquier litigio.

En particular, sobre la base de algunas observaciones formuladas por terceros financiadores en Suiza, parece que la mayoría de los procedimientos financiados por terceros implican demandantes financieramente fuertes. Éstos se sirven de la financiación de terceros para evitar asignar fondos sustanciales a los procedimientos judiciales, porque no desean que se vinculen cantidades importantes a lo largo de la duración de dichos procedimientos. $\mathrm{O}$ bien, las partes financieramente sólidas hacen arreglos para que la financiación por terceros diversifique o "externalice" totalmente el riesgo del litigio (traducción libre). (p. 2620)

\section{Las tendencias del TPF y sus nuevas oportunidades}

Llegados a este punto, hemos podido analizar qué es el TPF en el arbitraje internacional, qué antecedentes tiene y cuáles son sus mayores virtudes y puntos críticos; pero más allá de eso, el financiamiento de terceros atraviesa actualmente un escenario totalmente novedoso con multiplicidad de oportunidades y tendencias para el desarrollo 
de la figura, las cuales pueden hacer del TPF un tema común en cualquier arbitraje internacional en el futuro. Particularmente, este nuevo escenario se categoriza por las siguientes tendencias: I) un crecimiento exponencial en el uso del TPF en arbitrajes internacionales; II) la entrada a nuevos mercados en los que la figura es toda una novedad o era muy poco conocida; y III) la vivencia de una nueva era marcada por la regulación de la financiación de terceros a través de legislaciones domésticas, reglamentos arbitrales, normas de soft law, entre otros. De manera especial, consideramos esta última tendencia como la más importante de todas, tal y como lo detallaremos más adelante.

Con relación al primer punto, hay que decir que el uso y la industria del TPF han ido en aumento en los últimos 10 años (International Council for Commercial Arbitration [ICCA] y QMUL, 2018, pp. 18-19; Fuchs y Richman 2020, p. 73; Marquais y Grec, 2020, p. 50). Por ejemplo, la edición 2013 de la International Arbitration Survey detallaba que el $94 \%$ de los encuestados — que eran abogados representantes de empresas de diferentes sectores comerciales - no había recurrido a la financiación de terceros (QMUL y PricewaterhouseCoopers, 2013, p. 20); sin embargo, ya para la edición 2015 de la International Arbitration Survey, se conoció que el $39 \%$ de los encuestados había encontrado el TPF en su práctica profesional y el $12 \%$ lo había utilizado directamente (QMUL y White \& Case, 2015, p. 45) ${ }^{19}$. Esos números fueron en aumento, pues para la edición del 2018 de la encuesta en mención, se encontró que el 97 \% de los encuestados estaba familiarizado con el financiamiento de terceros y el $16 \%$ lo había utilizado directamente (QMUL y White \& Case, 2018, p. 24) 20.

Por consiguiente, la tendencia pareciera ir cada vez más en aumento y, si bien el $16 \%$ de uso del TPF en una encuesta parecería no brindar una cifra significativa, el crecimiento en la industria de la financiación de terceros no ha mostrado signos de desaceleración (ICCA y QMUL, 2018, p. 20). Justamente, este crecimiento no solo se puede evidenciar a la luz de la percepción de los integrantes de la comunidad arbitral como lo detallamos en el párrafo anterior; sino también —y fundamentalmente—desde la perspectiva del crecimiento económico que han tenido los propios terceros financiadores; por ejemplo, Burford Capital, que es una de las financistas más reconocidas a nivel mundial, experimentó un aumento en sus beneficios de aproximadamente el 400 \% entre el 2008 y el 2014 (Dos Santos, 2017, p. 928). Así mismo, en jurisdicciones como Australia se reporta que la industria de la financiación de terceros ha crecido un 20,1\% desde el 2015 hasta el 2020 (IBISWorld, 2020), situación semejante a lo que sucede en el Reino Unido, pues tal y como lo detallan Matray y Van Rompaey (2017):

19 Esta encuesta fue realizada entre una muestra diversa y amplia de practicantes, árbitros, académicos y otros grupos relacionados con el arbitraje internacional (QMUL y White \& Case, 2015, p. 51).

20 Esta encuesta fue realizada entre una muestra diversa y amplia de practicantes, árbitros, académicos y otros grupos relacionados con el arbitraje internacional (QMUL y White \& Case, 2018, p. 41). 
El TPF disfrutó de un crecimiento exponencial en los últimos años. Solo en el Reino Unido, el valor de los recursos gestionados por los fondos de terceros supera hoy en día los 1500 millones de libras esterlinas. Esto representa un crecimiento del $743 \%$ (procedente de 180 millones de libras esterlinas) desde el 2009 [...] Un ejemplo sorprendente de este crecimiento exponencial puede encontrarse en las cifras anuales del mayor financiador de terceros del mundo, Burford Capital, que cotiza en la Bolsa de Valores de Londres. Burford ha revelado un crecimiento del $75 \%$ en su negocio durante el 2016, con un récord de 378 millones de dólares comprometidos en treinta casos (un aumento del $83 \%$ respecto a la cifra de 2015) (traducción libre). (p. 176)

Por otra parte, en relación con la segunda tendencia que está atravesando el TPF, también se puede evidenciar que esta figura está entrando a nuevos mercados donde era poco o nada conocida (ICCA y QMUL, 2018, p. 18; Fuchs y Richman, 2020, p. 73). Así, respecto a esas nuevas regiones donde los financiadores están incursionando, resalta su reciente actividad en Europa, Latinoamérica y el Pacífico Asiático. Con relación a Europa, debe decirse que el financiamiento de terceros tiene una historia medianamente consolidada en jurisdicciones como Reino Unido, Alemania y Países Bajos; sin embargo, en el resto del viejo continente el TPF es un asunto relativamente reciente (Veljanovski, 2012, p. 448; Scherer, Goldsmith y Flechet, 2012, p. 210; Bench Nieuwveld y Shannon Sahani, 2017, p. 219).

Ante ese panorama de novedad, el TPF europeo está creciendo poco a poco (ICCA y QMUL, 2018, p. 34), particularmente en jurisdicciones como Bélgica y Suiza (Bench Nieuwveld y Shannon Sahani, 2017, pp. 220 y ss.) o Austria (Fuchs y Richman, 2020, pp. 90-91). Igualmente, en Francia algunas de las financiadoras de arbitrajes más importantes a nivel mundial como Burford Capital, Calunius Capital y Vannin Capital, han empezado a financiar un importante margen de arbitrajes en los últimos años (Fuchs y Richman, 2020, p. 78). Este crecimiento se debe en gran parte a que las jurisdicciones europeas no tienen legislaciones expresas que prohíban el financiamiento de terceros, así como al hecho de que sus tribunales han reconocido la validez de los acuerdos de financiación en algunos casos; además, un amplio número de esas jurisdicciones no pertenece al common law, por lo que no resultan obligadas de ninguna manera por las doctrinas del Barretry, Maintenance y Champerty (Bench Nieuwveld y Shannon Sahani, 2017, pp. 219-237; Fuchs y Richman, 2020, pp. 73 y ss.) $)^{21-22}$.

21 Jurisdicciones como Irlanda y Chipre si están sujetas a las prohibiciones del Barretry, Maintenance y Champerty por afiliarse al sistema jurídico del common law (Bench Nieuwveld y Shannon Sahani, 2017, pp. 222 y 227).

22 Igualmente, Mereminskaya (2017, pp. 10 y 11) resalta que en los ordenamientos jurídicos de afiliación con el Civil Law como España y Chile existe el principio de libertad de pactos, además de que ya son aceptadas figuras medianamente semejantes al TPF como lo son la venta de créditos litigiosos; por lo tanto, el TPF pareciera no tener mayor obstáculo legal en esos ordenamientos jurídicos. Esta conclusión podría extrapolarse a otras jurisdicciones latinoamericanas que, al igual que Chile, remontan sus raíces jurídicas al derecho continental europeo. 
De manera semejante, en el sector latinoamericano también se evidencia un crecimiento importante del financiamiento de terceros (ICCA y QMUL, 2018, p. 18). Si bien las cifras de casos financiados en America Latina parecen ser relativamente pequeñas (Krug y Eatock, 2018), el panorama arbitral latinoamericano se empieza a caracterizar por un conocimiento más activo del fenómeno del TPF; un mayor nivel de consultas por parte de los empresarios e inversionistas para conocer las ofertas de los terceros financiadores; un repunte en los casos financiados y la reciente creación de múltiples fondos de financiación de arbitrajes, específicamente en países como Brasil, Chile y Perú (Mereminskaya, 2017, p. 10; Krug y Eatock, 2018; Ramírez, 2018, pp. 47-51).

Ahora, la región en la que el TPF está entrando con un mayor impacto ha sido el Pacífico Asiático, la cual tiene un rol fundamental hoy en día para el desarrollo de la financiación por terceros en el arbitraje internacional, ya que en esta región se han gestado las primeras leyes domésticas que han regulado de manera íntegra el TPF en el mundo. No obstante, teniendo en cuenta que este asunto también trastoca la tercera tendencia que demarcamos relativa a la regulación del fenómeno de la financiación por terceros - la cual consideramos la más importante de todas-, pasaremos a hacer un análisis más detallado de esta situación en el acápite y las páginas que siguen.

\section{Una nueva era empieza. El TPF y su regulación en los últimos diez años}

Con relación al crecimiento del TPF en el Pacifico Asiático, son especialmente importantes los casos de Hong Kong y Singapur, quienes han modificado sus legislaciones para dar cabida al TPF en los arbitrajes internacionales que les tengan como sede (Bao, 2017, pp. 388 y ss.; Bajaj, Yang y Chan, 2020)23. Estas dos jurisdicciones —por su afiliación con el common law - tenían prohibidas la financiación de terceros de conformidad con las doctrinas del Barretry, Maintenance y Champerty; sin embargo, en el 2017, Hong Kong modificó su Ordenanza de Arbitraje para permitir el TPF, así como para informar que se establecería un Code of practice for Third Party Funding of Arbitration, el cual se emitió oficialmente en el 2018 y establece las prácticas que deben cumplir los financiadores de terceros en esa jurisdicción (The Government of the Hong Kong Special Administrative Region, 2018; Hirst y Yeow, 2019; Fuchs y Richman, 2020, p. 85). Igualmente, Singapur también modificó en el 2017 su Ley de Derecho Civil con el fin de permitir el TPF en su jurisdicción (Bao, 2017, pp. 390 y ss.; Secomb, Wallin y Richmond, 2019, pp. 171 y ss.).

Al respecto, la Ordenanza de Arbitraje de Hong Kong sostiene que "los delitos del common law de maintenance (incluido el delito de derecho consuetudinario de champerty) y

23 Cabe aclarar que en el caso de Hong Kong, su regulación también permitió el TPF para procesos de mediación; al respecto, véase el artículo 7A de la Ordenanza de Mediación de Hong Kong del 2012 [Cap. 620]. https://www.elegislation.gov.hk/hk/cap620?xpid=ID_1498202413400_001. Sobre Singapur, el TPF se permite en cualquier clase de procedimientos de resolución de controversias; al respecto, véase el artículo 5B de la Ley de Derecho Civil de Singapur del año 1999 [chapter 43]. https://sso.agc.gov.sg/Act/CLA1909\#pr5B- 
de ser un common barrator, no se aplican en relación con la financiación del arbitraje por parte de terceros" (traducción libre) ${ }^{24}$. En el mismo sentido, la Ley de Derecho Civil de Singapur dispone que "se declara que ninguna persona es, bajo la ley de Singapur, responsable en agravio por cualquier conducta a causa de su maintenance o champerty como lo conoce el derecho consuetudinario" (traducción libre) ${ }^{25}$. Ambas modificaciones son consecuentes con el hecho de que Hong Kong y Singapur sean parte de las cinco sedes más preferidas para arbitrajes internacionales (QMUL y White \& Case, 2018, p. 9), ya que siendo el TPF una cuestión en auge, no tendría ningún sentido que estas sedes tan importantes hubiesen mantenido las prohibiciones del Barretry, Maintenance y Champerty; además, a través de estas también se convierten en sedes más accesibles, pues abren las puertas a esos potenciales usuarios del arbitraje internacional que solo podrían acceder a este a través del TPF, así como también se hacen más llamativas para aquellos que lo usan como una forma de diversificar los riesgos de iniciar un arbitraje o por razones de flujo de caja (Bao, 2017, p. 400).

Igualmente, con estas legislaciones modernas ambos países se convierten en las primeras jurisdicciones en el mundo en regular el TPF por medio de leyes en el seno de sus ordenamientos jurídicos; siendo, a su vez, pioneras en una nueva etapa en el fenómeno que estudiamos: la regulación del TPF. La anterior afirmación se hace sin perjuicio de la condición reguladora que ya habían tenido jurisdicciones como Australia, donde actualmente se concibe al TPF como un producto financiero y, por tanto, a los terceros financiadores como entidades sujetas a la Ley de la Comisión de Inversiones y Valores de Australia del 2001 (Hashu, 2016, p. 103; Geisker y Luff, 2019, p. 4). En Australia —una de las jurisdicciones que tradicionalmente es de las más favorables al TPF en conjunto con el Reino Unido (Shannon Sahani, 2013, pp. 444-448; Bench Nieuwveld y Shannon Sahani, 2017, p. 75)—, el poder judicial fue creando algunas reglas relativas al TPF a partir de una serie de casos o decisiones judiciales (Bench Nieuwveld \& Shannon Sahani, 2017, pp. 83-91), lo que igualmente llevó a la Comisión de Inversiones y Valores a emitir algunas directrices o políticas al respecto (Shannon Sahani, 2013, pp. 444-446; Von Goeler, 2016, p. 110; Bench Nieuwveld \& Shannon Sahani, 2017, pp. 88 y ss.; Geisker \& Luff, 2019, pp. 4 y ss.).

Resulta innegable que Australia tiene un papel relevante en esta nueva etapa del TPF, pues son los primeros en regular la figura (Matray y Van Rompaey, 2017, p. 184); sin embargo, no podríamos considerar el caso australiano propiamente un caso de regulación con enfoque legislativo sobre el TPF, y menos uno de manera tan detallada como si lo hacen las legislaciones de Hong Kong y Singapur. Estas dos legislaciones estipulan qué es el TPF, quién puede ser un tercero financiador, cómo se evitarán las injerencias indebidas del financiador en las decisiones del financiado, aspectos éticos

24 Véase el apartado 10A, artículo 98K de la Ordenanza de Arbitraje de Hong Kong del año 2011 [Cap. 609]. https://www.elegislation.gov.hk/hk/cap609?tab=m\&xpid=ID_1498191921145_001

25 Véase el artículo 5A, numeral 1 de la Ley de Derecho Civil de Singapur del año 1999 [Chapter 43]. https://sso.agc.gov.sg/Act/CLA1909\#pr5B- 
del financiamiento de terceros, entre otros (Bao, 2017, pp. 396 y ss.; Milburn, 2019; Beechey, 2019, pp. 559-563). De lo anterior deriva la importancia de estas jurisdicciones para el desarrollo del TPF, pues no solo se convirtieron en nuevos mercados para el mismo, sino que de plano optaron por legislar la figura, algo que no se había hecho hasta el momento.

Así, con las legislaciones del Sudeste Asiático no solo se ratificó la tendencia regulatoria que había iniciado Australia, sino que también se demarcó una postura novedosa y relevante a nivel mundial sobre la cuestión del cómo regular, pues se prefirió el enfoque legislativo antes que cualquier otro. Tan relevante es este enfoque legislativo que, ya para el 2018, la provincia canadiense de Columbia Británica también modificó su Ley de Arbitraje Comercial Internacional, ello para definir qué es el TPF en esa jurisdicción y para destacar que el mismo no es contrario a su orden público (Montpetit, 2018) ${ }^{26}$. No obstante, debemos reconocer que aparte del enfoque legislativo existen otro tipo de iniciativas regulatorias sobre el TPF; por ejemplo, resaltan las autorregulaciones de algunas asociaciones de abogados o financiadores de terceros en jurisdicciones como Francia y Reino Unido.

En Francia, ante la ausencia de legislación que prohibiera expresamente el TPF, el Colegio de Abogados de París adoptó una resolución el 21 de febrero de 2017 sobre el financiamiento de terceros para arbitrajes internacionales, la cual respalda expresamente la práctica y hace énfasis en los deberes y estándares éticos que deben tener los abogados respecto al TPF (Rogers, Fitzgerald y Dowling, 2017, pp. 30-31; Fuchs y Richman, 2020, pp. 79-83; Marquais y Grec, 2020, p. 66). En relación con el Reino Unido, una agencia de su Ministerio de Justicia denominado Consejo de Justicia Civil en conjunto con la Association of Litigation Funders of England \& Wales (ALF), publicaron un Código de conducta voluntario para financiadores de litigios en el 2011 (Matray y Van Rompaey, 2017, p. 184; Fuchs y Richman, 2020, p. 74). A través de este, se regulan aspectos importantes respecto a los financiadores de terceros que deseen acogerse al reglamento, tales como la suficiencia mínima de su capital, los estándares de conducta que deben respetar los financiadores, entre otros temas; además, el Código de conduta también delega en la ALF la supervisión sobre el cumplimiento de esta autorregulación $(\text { ALF, s. f. })^{27}$.

26 Con esta legislación, se "ajusta la Columbia Británica a las modernas opiniones nacionales e internacionales sobre la financiación de terceros" (traducción libre) (Montpetit, 2018).

27 Sobre este Código, Fuchs y Richman (2020) sostienen que "El ALF está compuesto actualmente por 18 financiadores, entre los que se encuentran grandes actores como Burford Capital, Calunius Capital, Harbour Litigation Funding, Therium o Vannin Capital. El Código de la ALF ha sido descrito como un 'ejemplo pionero de autorregulación nacional de la industria de financiación de litigios' [...] Sin embargo, el instrumento no solo sigue siendo voluntario, sino que también es blando en lo que respecta a su aplicación. Las sanciones contempladas para las infracciones del Código de la ALF son esencialmente advertencias (privadas y públicas), la suspensión o la expulsión de la pertenencia a la ALF y la imposición de una multa monetaria hasta un límite de 500 libras esterlinas" (traducción libre) (p. 74). 
Adicionalmente, no solo jurisdicciones y asociaciones han decidido regular el TPF, pues en este mismo escenario también han entrado algunas instituciones arbitrales, quienes han regulado la figura en sus reglamentos de arbitraje. Así, destacan los casos del Hong Kong International Arbitration Centre (HKIAC), que regulan la figura en el artículo 44 de su Reglamento de arbitraje del año 2018 ${ }^{[28]}$, la Camera Arbitrale di Milano (CAM), que regula el TPF en el artículo 43 de sus reglas de arbitraje del 2020 [29], y, finalmente, el Centro Internacional de Arbitraje de Madrid (CIAM), quien ha sido de las últimas instituciones arbitrales en adherirse a esta tendencia con su Reglamento de arbitraje del 2020 , donde se regula la figura en el artículo $23^{[30]}$. Todas estas regulaciones se ocupan de las facultades que tiene el tribunal arbitral respecto de las partes que posiblemente hayan acudido a TPF y, especialmente, determinan el deber de estas de comunicar si están siendo financiadas y la identidad del financiador de terceros (Beechey, 2019, p. 577; Kamnani y Kaushal, 2019, p. 161; Maciel y Villarpando Pérez, 2020, p. 68).

En un sentido semejante al de las reglas de arbitraje de los centros que acabamos de identificar, pero en el campo de los arbitrajes entre inversionistas y Estados, el Singapore International Arbitration Centre (SIAC) reguló la figura en el artículo 24 de su Reglamento de arbitraje de inversiones del 2017, el cual brinda al Tribunal Arbitral la facultad de ordenar a una de las partes que devele si está siendo financiada en el arbitraje y la identidad del financiador ${ }^{31}$. En un tono muy similar, se dirigió la Beijing Arbitration Commission (BAC), que también reguló el TPF en el artículo 39 de su Reglamento de arbitraje de inversiones del 2019, aunque más allá del deber de revelación decidió incursionar en algunos otros aspectos como: I) definir qué es el TPF y II) emitir algunas reglas relativas a las security for costs en presencia de un acuerdo de financiamiento ${ }^{32}$.

Por otro lado, en el caso latinoamericano, el Centro de Arbitraje y Mediación de la Cámara de Comercio de Brasil-Canadá (CAM-CCBC) ha optado por emitir la Resolución administrativa AR 18/2016, en la cual brinda un concepto del TPF, detallan que el mismo puede generar conflictos de interés y, adicionalmente, recomiendan a las partes comunicar si están siendo financiadas y la identidad del financiador para evitar tales $\operatorname{conflictos}^{33}$. Si bien esta no es una regulación que vincule a las partes y les imponga deber alguno, determina un hito importante para el escenario latinoamericano del

Véase el artículo 44 del Reglamento de arbitraje del 2018 del HKIAC. https://www.hkiac.org/sites/ default/files/ck_filebrowser/PDF/arbitration/2018_hkiac_rules.pdf

29 Véase el artículo 43 del Reglamento de arbitraje del 2020 de la CAM. https://www.camera-arbitrale. it/upload/documenti/arbitrato/ARBITRATION\%20RULES\%202020.pdf

30 Véase el artículo 23 del Reglamento de arbitraje del 2020 del CIAM. https://madridarb.com/wpcontent/uploads/2020/04/REGLAMENTO_CIAM_DIGITAL-DEF2.pdf

31 Véase el artículo 24 del Reglamento de arbitraje de inversiones del año 2017 del SIAC. https://www. siac.org.sg/images/stories/articles/rules/IA/SIAC\%20Investment\%20Rules\%202017.pdf

32 Véase el artículo 39 del Reglamento de arbitraje de inversiones del año 2019 de la BAC. https://www. kluwerarbitration.com/

33 Véase la Resolución administrativa AR 18/2016 del CAM - CCBC. https://ccbc.org.br/cam-ccbc-centroarbitragem-mediacao/en/administrative-resolutions/ar-18-2016-recommendations-regarding-theexistence-of-third-party-funding-in-arbitrations-administered-by-cam-ccbc/ 
TPF, ya que si este fenómeno crece en America Latina también es lógico pensar que los problemas relativos a conflictos de interés y el TPF puedan manifestarse en este continente (Camayo Ortiz, 2020, p. 105).

Finalmente, en el campo de soft law también se han empezado a regular las cuestiones relativas a los terceros financiadores; por ejemplo, las Directrices de la International Bar Association (IBA) sobre conflictos de interés en el arbitraje internacional del año 2014 precisan que

Los terceros financiadores y las aseguradoras en relación a la disputa pueden tener un interés económico directo en el laudo, y por tanto pueden considerarse como equivalentes a la parte. A estos efectos, los términos "tercero financiador" y "aseguradora" se refieren a cualquier persona o entidad que contribuya con fondos, u otro tipo de apoyo material, al desarrollo del proceso en interés de la demanda o defensa del caso y que tenga un interés económico directo en, o un deber de indemnizar a una parte por, el laudo que se vaya a emitir en el arbitraje. ${ }^{34}$

Claramente la regulación en las Directrices IBA es somera, pues al fin y al cabo su objeto no era propiamente el financiamiento de terceros, sino los conflictos de interés que se puedan dar en el marco del arbitraje internacional; de hecho, las directrices no detallan mayor información sobre el fenómeno de la financiación de terceros que la que acabamos de citar. No obstante, en el 2018, la comunidad arbitral vio cómo incursionaba un conjunto de principios de soft law sobre el TPF: el Reporte del ICCA y QMUL sobre el TPF en el arbitraje internacional (ICCA y QMUL, 2018, pp. 14-16). Ponemos entre comillas el término soft law porque, si bien el objetivo principal de la fuerza de tarea conjunta entre estas dos organizaciones no fue emitir un reglamento de esa naturaleza — sino más bien entender las implicaciones del TPF en el arbitraje internacional y cómo estas deben ser tratadas (ICCA y QMUL, 2018, p. 6) —, los principios que han esbozado en su informe se han empezado a valorar como si fueran un reglamento de soft law sobre el TPF (QMUL y White \& Case, 2018, p. 36).

Este informe, aparte de ser el estudio más detallado, amplio y sistemático sobre el financiamiento de terceros en el arbitraje internacional (Beechey, 2019, p. 567; Henriques, 2019, p. 171), trae una serie de principios o directrices con relación a ciertas problemáticas del TPF, tal y como lo son los conflictos de interés y su solución a través del deber de revelación; la insolvencia económica de los financiados y su relación con las security for costs; entre otras (ICCA y QMUL, 2018, pp. 14-16). Ahora, más allá de que el informe ayude a entender el fenómeno del TPF y defina ciertos parámetros sobre la materia, su relevancia también deriva en el impacto que pueda tener este instrumento en las legislaciones o regulaciones de distintas jurisdicciones. Debe recordarse que "una de las funciones del soft law está dada por el estímulo hacia los Estados para que 
adopten legislación interna" (Feler, 2015, p. 296); así, autores como Kamnani y Kaushal (2019, p. 175) ya han sugerido la importancia de que los principios dados por el ICCA y el QMUL se adopten en la legislación india, un asunto que el informe podría incitar perfectamente en muchas otras jurisdicciones.

Es más, el informe del ICCA y el QMUL ya ha servido de inspiración para otro reglamento de soft law relativo al arbitraje internacional: el Código de Buenas Prácticas Arbitrales del Club Español de Arbitraje (CEA) del 2019, ya que este expresamente reconoce tomar como fuente los principios o directrices que trae el mencionado reporte $^{35}$. En este Código, aparte de tratarse otros temas del arbitraje internacional, se consagra el deber de revelar la financiación y la identidad del financiador como una buena práctica arbitral ${ }^{36}$, un deber que justamente fue amplia y fuertemente respaldado por el informe del ICCA y el QMUL sobre el TPF (Kreindler y Goldsmith, 2019, pp. 263 y 269).

\section{¿POR QUÉ REGULAR EL FENÓMENO DEL FINANCIAMIENTO DE TERCEROS?}

De toda esta gama de leyes, reglamentos, resoluciones y disposiciones de soft law, que acabamos de mencionar, se deriva una conclusión clara y evidente: la regulación del TPF en el plano del arbitraje internacional es toda una tendencia al día de hoy y, además, es una inclinación fuerte en algunas jurisdicciones; prueba de ello es que tan solo en diez años se gestaron multiplicidad de regulaciones sobre el financiamiento de terceros. No importa si el enfoque de regulación es legislativo, autorregulatorio o flexible como en los reglamentos de soft law, o si la iniciativa nace de un órgano público o de una organización privada, lo realmente importante es que los actores con influencia en el arbitraje internacional han visto la regulación como una cuestión necesaria para el fenómeno de la financiación por terceros.

Ahora, naturalmente esta postura no devino como iniciativa propia de los actores que regularon el TPF, sino de aquellos quienes encontraron en la regulación una posible solución a todas esas críticas que existen - y estudiamos en su mayoría párrafos atrás- en contra del financiamiento de terceros (Von Goeler, 2016, pp. 103-104; Hashu, 2016 , pp. 89 y ss.). En ese sentido, parece que en el arbitraje internacional ha surgido una "escuela de pensamiento" que detalla la necesidad de que se regule la figura del TPF (Henriques, 2017, p. 117); perspectiva que, incluso, también es defendida por los propios miembros de la comunidad arbitral. Por ejemplo, la ya citada edición 2015 de la International Arbitration Survey demuestra que el $71 \%$ de sus encuestados considera

$35 \mathrm{Al}$ respecto, véase la página 17 del Código de Buenas Prácticas Arbitrales del CEA. https://www. garrigues.com/sites/default/files/documents/codigo_de_buenas_practicas_arbitrales_del_club_espanol_del_arbitraje.pdf

36 Al respecto, véase la sección sexta del del Código de Buenas Prácticas Arbitrales del CEA. https://www. garrigues.com/sites/default/files/documents/codigo_de_buenas_practicas_arbitrales_del_club_espanol_del_arbitraje.pdf 
que el fenómeno del financiamiento de terceros requiere de mayor regulación (QMUL y White \& Case, 2015, p. 37) $)^{37}$.

Sin embargo, esta tendencia de la que hemos venido hablando, va en contravía de lo que cierto sector de la doctrina considera es la herramienta que permitiría el desarrollo del TPF: la jurisprudencia. Al respecto, Bench Nieuwveld y Shannon Sahani (2017) sostienen que "el futuro crecimiento y desarrollo de la industria de la financiación por terceros dependerá en gran medida de la orientación de la jurisprudencia" (traducción libre) (p. 13). Esa postura, en nuestro criterio, resulta un tanto difícil de sostener, pues tal y como pareciera responder la propia jurisprudencia en el caso Waterhouse vs. Contractors Bonding Limited de la Corte Suprema de Nueva Zelanda del 2013, "no es función de los tribunales actuar como reguladores generales de los acuerdos de financiación de litigios. Si se considera conveniente, ello es una cuestión de legislación o reglamentación" (traducción libre) ${ }^{38}$. Además, bien añade Von Goeler (2016), al comentar la sentencia en mención, que:

Esto es aún más cierto en el caso de los tribunales arbitrales, ya que el mandato de los árbitros como jueces privados, basado en el consentimiento, conlleva funciones de supervisión y vigilancia reglamentaria mucho más limitadas (si es que las hay) que las que puede ejercer un tribunal nacional, especialmente un Tribunal Supremo (traducción libre). (p. 143)

Evidentemente, la afirmación de que el futuro crecimiento y desarrollo del TPF "dependerá en gran medida de la orientación de la jurisprudencia" (traducción libre) (Bench Nieuwveld y Shannon Sahani, 2017, p. 13), se hizo con antelación a las modificaciones de las leyes de Hong Kong y Singapur, a los reglamentos de arbitraje de algunas instituciones arbitrales, al informe del ICCA y el QMUL sobre el TPF, entre otros; lo que hacía imposible prever que en tan poco tiempo la tendencia a la regulación se haría tan fuerte. Pero, en todo caso, evidenciando que es difícil justificar la tesis de que el desarrollo del TPF viene de la mano de la jurisprudencia, proponemos reconsiderar la misma sosteniendo que el futuro crecimiento del financiamiento de terceros dependerá, principalmente, de su regulación.

Por supuesto, la tendencia a la regulación aún está en auge, sobre todo si se tiene en cuenta que el TPF es fenómeno mundial y las regulaciones que hemos estudiado solo han ocurrido en algunas pocas jurisdicciones o instituciones arbitrales (Mazzoni, 2019, p. 305 ${ }^{39}$; por lo que es válido decir que la regulación del financiamiento de

37 Esta encuesta fue realizada entre una muestra diversa y amplia de practicantes, árbitros, académicos y otros grupos relacionados con el arbitraje internacional: (QMUL y White \& Case, 2015, p. 51).

38 Véase Corte Suprema de Nueva Zelanda (20 de septiembre de 2013) Waterhouse vs. Contractors Bonding Limited (2013) NZSC 89. https://www.courtsofnz.govt.nz/cases/waterhouse-v-contractorbonding-ltd

39 Salvo, por supuesto, el informe del ICCA y QMUL sobre el TPF y el Código de Buenas Prácticas Arbitrales del CEA que, como normas o directrices de soft law, no se encontrarían vinculadas a una jurisdicción en particular. 
terceros apenas si atraviesa su etapa de "infancia" (traducción libre) (Von Goeler, 2016, p. 118). Encima también es cierto que otras tendencias del TPF como su crecimiento exponencial y su llegada a nuevos mercados son determinantes para el futuro de la figura, pues permiten pensar que la industria está consiguiendo su consolidación poco a poco en el mercado, convirtiendo al TPF en un tema central del arbitraje internacional y no solo en una mera realidad de este.

No obstante, a pesar de lo anterior, creemos que la regulación tendrá un mayor impacto e importancia para el futuro crecimiento y desarrollo del TPF, ya que esta tendencia: I) permite tener una identidad más clara sobre la figura del financiamiento de terceros; II) logra alcanzar la validez de los acuerdos de financiación en jurisdicciones que, como Hong Kong y Singapur, prohibían el TPF por virtud de las doctrinas del Barretry, Maintenance y Champerty; y III) sirve como un elemento activo para solucionar las críticas más fuertes que se han hecho en contra del fenómeno que analizamos. Respecto a la identidad más clara de la figura, vale decir que el TPF no gozaba de un concepto único, generalizado y universal (Osmanoglu, 2015, p. 329; Stoyanov y Owczarek, 2015, p. 189); sin embargo, con la regulación del TPF se está gestando una conceptualización de la figura medianamente pacífica y uniforme. Por ejemplo, la Ordenanza de Arbitraje de Hong Kong establece que:

La financiación del arbitraje por terceros es la provisión de fondos para un arbitraje: a) en virtud de un acuerdo de financiación; b) a una parte financiada; c) por un tercero financiador $;$ y d) a cambio de que el tercero financiador reciba un beneficio financiero solo si el arbitraje tiene éxito en el sentido del acuerdo de financiación (traducción libre). ${ }^{40}$

Igualmente, la Ley de Arbitraje Comercial Internacional de la Columbia Británica sostiene que:

"financiación de terceros", en relación con un arbitraje, significa la financiación del arbitraje que se proporciona: a) a una parte en el acuerdo de arbitraje por una persona que no sea parte en ese acuerdo, y b) en consideración a que la persona que proporciona la financiación reciba un beneficio económico si la parte financiada tiene éxito en el arbitraje (traducción libre) ${ }^{41}$

40 Véase el apartado 10A, artículo 98G de la Ordenanza de Arbitraje de Hong Kong del año 2011 [Cap. 609]. https://www.elegislation.gov.hk/hk/cap609?tab=m\&xpid=ID_1498191921145_001

41 Véase el artículo 36, numeral 4 de la Ley de Arbitraje Comercial Internacional de la Columbia Británica del año 1996 [RSBC 1996]. https://www.bclaws.gov.bc.ca/civix/document/id/complete/ statreg/96233_01\#: :text=1\%20(1)\%20This\%20Act\%20applies,which\%20applies\%20in\%20British $\% 20$ Columbia.\&text=(c)\%20 the $\% 20$ parties $\% 20$ have $\% 20$ expressly, to $\% 20$ more $\% 20$ than $\% 20$ one $\% 20$ state 
A su vez, el informe del ICCA y el QMUL sobre el TPF preceptúa:

La expresión "financiación de terceros" se refiere al acuerdo de una entidad que no es parte en una controversia de proporcionar a una parte, una filial de esa parte o un bufete de abogados que la represente: a) fondos u otro apoyo material para financiar parcial o totalmente los gastos del procedimiento, ya sea individualmente o como una serie de casos concretos; y b) que ese apoyo o financiación se proporcione a cambio de una remuneración o un reembolso que dependa total o parcialmente del resultado de la controversia, o se proporcione mediante una subvención o a cambio del pago de una prima (traducción libre). (2018, p. 50)

En el plano latinoamericano, el CAM-CCBC también acoge un concepto similar en su Resolución administrativa AR 18/2016 al estipular que

Se considera financiación de terceros cuando una persona física o jurídica que no es parte en el procedimiento de arbitraje proporciona recursos totales o parciales a una de las partes para permitir o ayudar al pago de las costas del arbitraje, recibiendo a cambio una parte o un porcentaje de los beneficios obtenidos del laudo o del acuerdo (traducción libre). ${ }^{42}$

Como se puede evidenciar, el concepto de TPF en estas regulaciones es tangencialmente el mismo, lo que implica cierto margen de uniformidad en su trato; además, estos conceptos también acogen la condición de que el TPF es un negocio de inversión que debe sus riesgos al resultado de la disputa, tal y como lo había detallado la doctrina de tiempo atrás. No obstante, a pesar de que la academia había medianamente decantado un concepto del TPF, el asunto no era por entero pacifico, ya que algunos sostenían que era difícil proporcionar una definición precisa de la figura sin que existiera una regulación que lo detallase (Von Goeler, 2016, p. 329). En ese sentido, las recientes regulaciones del TPF son claramente beneficiosas, ya que con ellas se trasciende de un concepto que nace de los aportes teóricos a uno con la naturaleza de un precepto jurídico aplicable a un caso en concreto. Por supuesto, las regulaciones que hemos resaltado no obligan en cualquier arbitraje internacional, pues se deberá tener en cuenta si resultan ley aplicable a un determinado arbitraje; sin embargo, fungen como un parámetro para prever que, si en el futuro habrá más regulaciones sobre el TPF, también habrá un concepto cada vez más generalizado y universal.

En relación con el segundo impacto que tiene la regulación del TPF, relativo a conseguir su validez en jurisdicciones donde puede estar prohibido por virtud de las doctrinas del Barretry, Maintenance y Champerty, debe decirse que este puede ser uno de los aportes más significativos que traiga la regulación de este fenómeno. Ya

42 Véase el artículo 1 de la Resolución administrativa AR 18/2016 del CAM-CCBC. https://ccbc.org.br/ cam-ccbc-centro-arbitragem-mediacao/en/administrative-resolutions/ar-18-2016-recommendationsregarding-the-existence-of-third-party-funding-in-arbitrations-administered-by-cam-ccbc/ 
identificamos como Hong Kong y Singapur permitieron el TPF únicamente a través de una ley que desestimó las doctrinas en mención, empero, estamos hablando de solo dos jurisdicciones de una amplia mayoría que se afilian al sistema jurídico del common law, donde el Maintenance y sus variables podrían imposibilitar la práctica de la financiación de terceros. Precisamente, de allí deriva la importancia de la regulación sobre este asunto, pues de nada sirve que el TPF crezca exponencialmente en su uso si en el futuro se encontrará con jurisdicciones que impidan su presencia; además, los nuevos mercados del TPF en el futuro serán justamente aquellos donde la práctica es actualmente prohibida, tal y como hoy lo son las jurisdicciones de Singapur y Hong Kong.

Por otro lado, si bien hay que reconocer que jurisdicciones como Reino Unido y Australia no se hicieron favorables al TPF por medio de una reforma legislativa o por cualquier otra clase de regulación, también debe reconocerse que los procesos para que ello ocurriera llevaron años (Lord Neuberger, 2013, pp. 7-19; Bench Nieuwveld y Shannon Sahani, 2017, p. 93; Geisker y Luff, 2019, pp. 2 y ss.). Este proceso podría aminorarse a través de una legislación, tal y como lo hizo la Columbia Británica con la modificación a su Ley de Arbitraje Comercial Internacional, por la cual se dispone que "la financiación de terceros para un arbitraje no es contraria al orden público de la Columbia Británica" (traducción libre) ${ }^{43}$. Es más, jurisdicciones como Malasia ya han anunciado reformas a su ley de arbitraje en un sentido similar al de Hong Kong, Singapur y la Columbia Británica (Bajaj, Yang y Chan, 2020).

Finalmente, la regulación también está empezando a prever importantes soluciones a las críticas más fuertes que existen en contra del financiamiento de terceros. Por ejemplo, en relación con los posibles conflictos de interés que puedan existir con ocasión del TPF, la Ordenanza de Arbitraje de Hong Kong estableció el deber de las partes de revelar la financiación y la identidad del financiador como una forma de evitarlos:

(1) Si se hace un acuerdo de financiación, la parte financiada debe dar aviso por escrito de: a) el hecho de que se haya celebrado un acuerdo de financiación, y b) el nombre del tercero que lo financió.

(2) La notificación debe ser dada: a) por un acuerdo de financiación celebrado en el momento de iniciarse el arbitraje o con anterioridad a éste, o b) dentro de los 15 días siguientes a la firma del acuerdo de financiación para acuerdos pactados después de iniciado el arbitraje.

43 Véase el artículo 36, numeral 3 de la Ley de Arbitraje Comercial Internacional de la Columbia Británica del año 1996 [RSBC 1996]. https://www.bclaws.gov.bc.ca/civix/document/id/complete/ statreg/96233_01\#: :text=1\%20(1)\%20This\%20Act\%20applies, which\%20applies\%20 in\%20 British\%20Columbia.\&text $=(\mathrm{c}) \% 20$ the $\% 20$ parties\%20have\%20 expressly, to\%20more\%20than\%20 one $\% 20$ state 
(3) La notificación debe ser dada a: a) cada una de las otras partes en el arbitraje, y b) el órgano del arbitraje (traducción libre). ${ }^{44}$

Este mismo deber de revelación que intenta evitar los conflictos de interés de los árbitros también está presente en los reglamentos de arbitraje del HKIAC ${ }^{45}, \mathrm{CAM}^{46}$, CIAM $^{47}$ y el BAC ${ }^{48}$; la Resolución administrativa AR 18/2016 del CAM-CCBC —aunque reiteramos que la revelación en esta resolución se hace como una recomendación para las partes - ${ }^{49}$; y en el Código de Buenas Prácticas del CEA ${ }^{50}$ y el Informe del ICCA y QMUL sobre el TPF (2018, p. 14). De tal manera, a la luz de la tendencia reguladora se está imponiendo el deber de revelación que la doctrina tanto había pregonado como solución a los eventuales conflictos de interés que puede desencadenar el TPF (Frignati, 2016, p. 516; Bench Nieuwveld y Shannon Sahani, 2017, p. 70; Theoduloz, 2019, p. 176), lo que sin duda alguna demuestra que la regulación tiene un factor útil y práctico al momento de resolver los problemas más graves que presenta la financiación de terceros.

Igualmente, la tendencia reguladora también parece estar resolviendo otro tipo de críticas, tales como la relativa a las security for costs incoadas ante un acuerdo de financiación. Así, el informe del ICCA y el QMUL propone que: "la solicitud de security for costs debe determinarse, en primer lugar, sobre la base de la prueba aplicable, sin tener en cuenta la existencia de cualquier acuerdo de financiación" (traducción libre) (ICCA y QMUL, 2018, p. 16). Es decir, "el punto de partida de todo tribunal que se enfrente a una solicitud de security for costs es, al menos, una prueba prima facie de que es improbable que el demandante pueda pagar una indemnización por costas adversas" (traducción libre) (ICCA y QMUL, 2018, p. 168), lo que no puede pregonarse de un acuerdo de financiamiento porque el mismo no representa clara prueba de la insolvencia económica del financiado (ICCA y QMUL, 2018, pp. 180-183).

Además, la regulación también está profesionalizando la actividad de los terceros financiadores, con lo que se evitan las posibles prácticas abusivas y poco éticas o

Véase el apartado 10A, artículo 98U de la Ordenanza de Arbitraje de Hong Kong del año 2011 [Cap. 609]. https://www.elegislation.gov.hk/hk/cap609?tab=m\&xpid=ID_1498191921145_001

45 Véase el artículo 44 del Reglamento de arbitraje del año 2018 del HKIAC. https://www.hkiac.org/ sites/default/files/ck_filebrowser/PDF/arbitration/2018_hkiac_rules.pdf

46 Véase el artículo 43 del Reglamento de arbitraje del año 2020 de la CAM. https://www.cameraarbitrale.it/upload/documenti/arbitrato/ARBITRATION\%20RULES\%202020.pdf

47 Véase el artículo 23 del Reglamento de arbitraje del año 2020 del CIAM. https://madridarb.com/ wp-content/uploads/2020/04/REGLAMENTO_CIAM_DIGITAL-DEF2.pdf

48 Véase el artículo 39 del Reglamento de arbitraje de inversiones del año 2019 de la BAC. https://www. kluwerarbitration.com/

49 Véase el artículo 4 de la Resolución administrativa AR 18/2016 del CAM - CCBC. https://ccbc.org.br/ cam-ccbc-centro-arbitragem-mediacao/en/administrative-resolutions/ar-18-2016-recommendationsregarding-the-existence-of-third-party-funding-in-arbitrations-administered-by-cam-ccbc/

50 Al respecto, véase la sección sexta del Código de Buenas Prácticas Arbitrales del CEA. https://www. garrigues.com/sites/default/files/documents/codigo_de_buenas_practicas_arbitrales_del_club_espanol_del_arbitraje.pdf 
profesionales por parte de estos; por ejemplo, el Código de Conducta de la ALF en el Reino Unido es claro en manifestar que:

Nada de lo dispuesto en el presente Código se interpretará en el sentido de que prohíba a un Financista llevar a cabo la debida diligencia, tanto antes de ofrecer financiación como durante el curso de los procedimientos de litigio que se estén financiando, incluyendo, entre otras cosas, el análisis de la ley, los hechos, los testigos y los costos relacionados con una reclamación, e incluyendo la revisión periódica del progreso del litigio (traducción libre). ${ }^{51}$

En sentido semejante, el Code of practice for Third Party Funding of Arbitration de Hong Kong — establecido en virtud de la modificación legislativa del 2017 a su Ordenanza de Arbitraje - estipula que "el tercero financiador debe [...] tomar las medidas razonables para asegurarse de que la parte financiada ha recibido asesoramiento jurídico independiente sobre el acuerdo de financiación antes de concertarlo" (traducción libre), a lo que luego añade que también deberá "establecer y explicar claramente en el acuerdo de financiación todas las características, riesgos y condiciones fundamentales de la financiación propuesta y el acuerdo de financiación" (traducción libre) ${ }^{52}$. Encima, tanto el Código de Conducta de la ALF del 2018 en su artículo 10 ${ }^{[53]}$, como el Code of practice for Third Party Funding of Arbitration de Hong Kong del 2018 en su artículo $2.12^{[54]}$ obligan a los financiadores de terceros a detallar claramente en el acuerdo de financiación si están o no obligados a responder por una eventual condena en costas contra la parte financiada, así como si están o no obligados a constituir una security for costs en caso de ser solicitada.

Como se puede apreciar, la regulación del financiamiento de terceros trae grandes beneficios en cuanto al futuro crecimiento y desarrollo de la figura, lo que — desde nuestra perspectiva - implica un argumento sólido para propugnar por la regulación del TPF en el arbitraje internacional. Ahora, vale destacar que estos beneficios de la regulación los hemos identificado a partir de las regulaciones existentes sobre el TPF, las cuales se han dado principalmente en el ámbito del arbitraje comercial internacional, tal y como es el caso de las modificaciones legislativas del 2017 a la Ordenanza de Arbitraje de Hong Kong y la Ley de Derecho Civil de Singapur; los reglamentos de arbitraje del HKIAC, CAM y CIAM; el Código de Buenas Prácticas Arbitrales del CEA; entre otros. No obstante, esos beneficios también podrían evidenciarse en las futuras regulaciones sobre el TPF o en aquellas que actualmente se encuentran en trámite y, en

51 Véase el artículo 16 del Código de Conducta de la ALF. https://associationoflitigationfunders.com/ code-of-conduct/

52 Véase el artículo 2.3 del Code of practice for Third Party Funding of Arbitration de Hong Kong del año 2018. https://www.info.gov.hk/gia/general/201812/07/P2018120700601.htm

53 Véase el artículo 10 del Código de Conducta de la ALF. https://associationoflitigationfunders.com/ code-of-conduct/

54 Véase el artículo 2.12 del Code of practice for Third Party Funding of Arbitration de Hong Kong del año 2018. https://www.info.gov.hk/gia/general/201812/07/P2018120700601.htm 
ese escenario, las reformas en el campo de los arbitrajes entre inversionistas y Estados tienen un rol preponderante.

En específico, destacan las labores del Grupo de Trabajo número III de la Comisión de las Naciones Unidas para el Derecho Mercantil Internacional (CNUDMI) por reformar el Sistema de Solución de Controversias entre Inversionistas y Estados (ISDS por Investor-State Dispute Settlement), así como el trabajo al interior del CIADI por modificar sus reglas y reglamentos internos, incluido su reglamento de arbitraje. Antes de entrar a analizar las posibles regulaciones que se deriven de estas dos iniciativas, es importante anotar que el TPF en el campo de los arbitrajes entre inversionistas y estados ha recibido mucha resistencia (ICCA y QMUL, 2018, pp. 199 y ss.; Brown de Vejar y Baldwin, 2019, pp. 540-555; Shannon Sahani, 2020, pp. 273-274; Walck, 2020, pp. 124-126), lo cual ha permeado fuertemente el debate sobre las reformas que se plantean tanto en el CIADI como en el Grupo de Trabajo número III respecto al tema del financiamiento de terceros.

Por ejemplo, el Grupo de Trabajo adoptó muy temprano en sus discusiones una postura de preocupación hacia la presencia del TPF en el ISDS ${ }^{55}$, una postura que se ha mantenido casi intacta a lo largo de las múltiples sesiones que han venido desarrollan$\mathrm{do}^{56}$. En particular, esa preocupación hacia al TPF ha sido sustentada en la ausencia de reglas claras y uniformes sobre el financiamiento de terceros en el arbitraje de inversiones, la posibilidad de que esta figura desencadene conflictos de interés en los procedimientos arbitrales, el incentivo a demandas temerarias que podría generar este fenómeno, entre otras críticas ${ }^{57}$. Ante ese panorama, el Grupo de Trabajo número III decidió plantear dos posibles enfoques como solución a la problemática: I) prohibir por completo la financiación de terceros en el marco de las disputas entre inversionistas y

55 Al respecto, véase el informe del Grupo de Trabajo III sobre la labor realizada en su $34 .^{\circ}$ periodo de sesiones (19 de diciembre de 2017) documento A/CN.9/930/Rev.1, pp. 10 y 12. https://undocs.org/ en/A/CN.9/930/Rev.1

56 Al respecto, véase el informe del Grupo de Trabajo III sobre la labor realizada en su $35 .^{\circ}$ periodo de sesiones (14 de mayo de 2018) documento A/CN.9/935, p. 15. https://undocs.org/es/A/CN.9/935; el informe del Grupo de Trabajo III sobre la labor realizada en su $36^{\circ}$ periodo de sesiones (6 de noviembre de 2018) documento A/CN.9/964, p. 20. https://undocs.org/en/A/CN.9/964; el informe del Grupo de Trabajo III sobre la labor realizada en su 37. ${ }^{\circ}$ periodo de sesiones (9 de abril de 2019) documento A/CN.9/970, pp. 5 y ss. https://undocs.org/en/A/CN.9/970; el informe del Grupo de Trabajo III sobre la labor realizada en su $38{ }^{\circ}$ periodo de sesiones (23 de octubre de 2019) documento A/CN.9/1004, pp. 17 y ss. https://undocs.org/en/A/CN.9/1004.

57 Al respecto, véase el informe del Grupo de Trabajo III sobre la labor realizada en su $35 .^{\circ}$ periodo de sesiones (14 de mayo de 2018) documento A/CN.9/935, p. 15. https://undocs.org/es/A/CN.9/935; el informe del Grupo de Trabajo III sobre la labor realizada en su $36 .^{\circ}$ periodo de sesiones ( 6 de noviembre de 2018) documento A/CN.9/964, p. 20. https://undocs.org/en/A/CN.9/964; el informe del Grupo de Trabajo III sobre la labor realizada en su $37 .^{\circ}$ periodo de sesiones (9 de abril de 2019) documento A/CN.9/970, pp. 5 y ss. https://undocs.org/en/A/CN.9/970; el informe del Grupo de Trabajo III sobre la labor realizada en su $38 .{ }^{\circ}$ periodo de sesiones (23 de octubre de 2019) documento A/CN.9/1004, pp. 17 y ss. https://undocs.org/en/A/CN.9/1004. 
estados; o II) regular íntegramente la figura en dicho ámbito ${ }^{58}$. Así mismo, la situación con relación a la iniciativa del CIADI por modificar sus reglamentos y reglas internas no ha sido del todo distinta, ya que algunos Estados contratantes del Convenio CIADI también propusieron que se prohibiera el TPF en las enmiendas que eventualmente fueran a realizarse (CIADI, 2018, p. 131).

No obstante, parece que el debate sobre la eventual prohibición del TPF en el ámbito de las disputas entre inversionistas y estados no tiene mayor futuro. En el caso del CIADI, el documento de trabajo número 1 sobre las enmiendas a las reglas y reglamentos de esa institución arbitral descartó de plano dicha posición, ya que esa postura se había justificado con base a que el TPF alienta la presentación de demandas frívolas o no meritorias, lo cual se consideró como un argumento incorrecto; además, también se determinó que las reglas del CIADI tenían distintos mecanismos para responder efectivamente a los eventos de reclamos frívolos o no meritorios (CIADI, 2018, p. 131). En el caso del Grupo de Trabajo número III de la CNUDMI se sostiene que, si bien existe cierto margen de apoyo al interior del Grupo por prohibir el financiamiento de terceros, la opinión general de los miembros es que debe permitirse el TPF en el marco del ISDS, siempre que esta figura sea efectivamente regulada ${ }^{59}$.

Ambas posturas son supremamente relevantes, ya que a partir de estas iniciativas de reforma se permitiría expresamente el TPF en el arbitraje de inversiones; es decir, pasaría algo semejante a lo ocurrido con las modificaciones legislativas de Hong Kong y Singapur que permitieron el TPF, pero ya no con relación a jurisdicciones en particular sino en el campo del ISDS en general. Así, la tendencia a la regulación no solo permitiría el TPF en jurisdicciones donde ese fenómeno estaría prohibido en virtud de las doctrinas del Barretry, Maintenance y Champerty, sino también en el pleno del ISDS donde la práctica ha encontrado fuertes críticas y sectores que buscan prohibirla (Shannon Sahani, 2020, pp. 273-274; Güven, Lockhart \& Garcia, 2020, pp. 292-299; Burghetto, 2020, p. 85; Walck, 2020, pp. 124-126). Además, al igual que con los beneficios detallados a partir de las regulaciones existentes sobre el TPF, las iniciativas del CIADI y el Grupo de Trabajo número III también podrían ayudar a resolver las críticas en contra de este fenómeno, ya que al fin y al cabo el propósito de estas al regular el TPF es precisamente resolver esas problemáticas.

Por ejemplo, en relación con la crítica de los conflictos de interés, las enmiendas del CIADI a su reglamento de arbitraje proponen una develación del financiamiento de terceros en los siguientes términos:

(1) Una parte presentará una notificación por escrito revelando el nombre y la dirección de cualquier tercero de quien la parte, directa o indirectamente, haya recibido fondos

58 Al respecto, véase el informe del Grupo de Trabajo III sobre la labor realizada en su $35 .^{\circ}$ periodo de sesiones (14 de mayo de 2018) documento A/CN.9/935, p. 15. https://undocs.org/es/A/CN.9/935.

59 Al respecto, véase el informe del Grupo de Trabajo III sobre la labor realizada en su $38 .^{\circ}$ periodo de sesiones (23 de octubre de 2019) documento A/CN.9/1004, p. 17. https://undocs.org/en/A/CN.9/1004. 
para la interposición de, o defensa en un procedimiento a través de una donación o una subvención, o a cambio de una remuneración dependiente del resultado del procedimiento ("financiamiento por terceros").

(2) El tercero al que se refiere el párrafo (1) no incluye al representante de una parte.

(3) La parte presentará la notificación a la que se refiere el párrafo (1) al secretario general al momento del registro de la solicitud de arbitraje o, en su caso, inmediatamente después de concluir el acuerdo de financiamiento si sucede después del registro. La parte comunicará inmediatamente al secretario general cualquier cambio en el contenido de la notificación.

(4) El secretario general transmitirá la notificación de financiamiento por terceros y cualquier comunicación sobre cambios a la información contenida en dicha notificación a las partes y a cualquier árbitro propuesto para nombramiento o nombrado en el procedimiento a efectos de completar la declaración de árbitro requerida por la Regla 19(3)(b).

(5) El Tribunal podrá ordenar la revelación de información adicional respecto al acuerdo de financiamiento y al tercero financiador en virtud de la Regla 36(3) si lo considera necesario en cualquier momento del procedimiento. (CIADI, 2020, p. 39)

Igualmente, a pesar de que el Grupo de Trabajo número III aún no adoptado una propuesta de regulación concreta, este sostiene que "debería revelarse la circunstancia de que la financiación sería proporcionada por terceros, así como la identidad de estos en una etapa temprana del proceso, o tan pronto como se concluyera el acuerdo de financiación"60. Por otro lado, respecto al tema de las security for costs, las enmiendas al Reglamento de arbitraje CIADI proponen en su artículo 53(4) que la existencia de financiamiento de terceros no implica, por sí sola, prueba suficiente para emitir una orden de esa naturaleza (CIADI, 2020, pp. 61-62) ${ }^{61}$. En el mismo sentido, el Grupo de Trabajo III entiende que la mera existencia de un acuerdo de financiación de terceros no es suficiente para otorgar la security for costs, ya que el TPF también se puede usar para gestionar los costos y riesgos asociados al ISDS, lo cual demuestra que el financiamiento de terceros no siempre implica la insolvencia económica del financiado ${ }^{62}$.

A parte, el Grupo de Trabajo también podría adoptar una reforma muy importante en materia de deberes éticos y profesionales de los terceros financiadores que invierten en disputas sobre inversiones. Al respecto, este Grupo solicitó a la Secretaría de la CNUDMI que elaborara un proyecto de disposiciones sobre el TPF que refleje las reformas

60 Al respecto, véase el informe del Grupo de Trabajo III sobre la labor realizada en su $38 .^{\circ}$ periodo de sesiones (23 de octubre de 2019) documento A/CN.9/1004, p. 18. https://undocs.org/en/A/CN.9/1004.

61 Sobre una explicación del enfoque que acoge el CIADI con en esta postura respecto al tema de las security for costs, véase con más detalle a Rueda-García (2020, pp. 112-119).

62 Al respecto, véase el informe del Grupo de Trabajo III sobre la labor realizada en su $38 .^{\circ}$ periodo de sesiones (23 de octubre de 2019) documento A/CN.9/1004, p. 19. https://undocs.org/en/A/CN.9/1004. 
y soluciones que podrían ser adoptadas para el ISDS en esa materia ${ }^{63}$, proyecto en el cual se planteó la posibilidad de un Código de Ética para los financiadores de terceros:

el Grupo de Trabajo quizás desee estudiar la posibilidad de elaborar un conjunto de normas por las que se rija la actividad profesional de los terceros que aportan financiación en el ámbito del ISDS, las cuales podría adoptar, por ejemplo, la forma de un código de ética. En estas normas se podrían establecer los requisitos mínimos de cualificación profesional, transparencia y confidencialidad. El Grupo de Trabajo tal vez también quiera examinar la conveniencia de introducir en ese código normas que limiten la influencia de los terceros financiadores en el procedimiento arbitral, en particular respecto de cuestiones delicadas como la selección de los árbitros y las negociaciones orientadas a resolver la controversia, así como la posibilidad de establecer un límite para la remuneración de los financiadores (traducción libre) ${ }^{64}$

Claramente, tanto la iniciativa del CIADI como la del Grupo de Trabajo número III aún se encuentran en desarrollo, cuestión por la que podrían estar sujetas a cambios en un futuro cercano. No obstante, de su análisis es dable concluir que dichas iniciativas parecen reportar los mismos beneficios que hasta el momento han reportado las regulaciones en el campo del arbitraje comercial internacional; es decir, la regulación lograría que el TPF sea explícitamente válido en los arbitrajes sobre inversiones y, además, también permitirá resolver las críticas en contra de esta figura, aspectos claramente beneficiosos para el desarrollo del TPF en el arbitraje de inversiones. Por otro lado, no sobra anotar que es interesante como se ha ido desarrollando la tendencia a la regulación en este ámbito, pues la regulación se ha tomado como la única alternativa viable para tratar el tema del TPF, bien para permitir la práctica de manera regulada o bien para prohibirla por completo en el marco del ISDS. Por ejemplo, en el reporte entregado por la Secretaría de la CNUDMI al Grupo de Trabajo III, se sostiene como una conclusión que:

El Grupo de Trabajo tal vez desee examinar los diversos medios para llevar a cabo una reforma relacionada con la financiación de terceros en el marco de las controversias sobre inversiones. Se podrían elaborar disposiciones que prohíban o regulen la financiación de terceros para integrarlas en los reglamentos de arbitraje, ya sea en forma de cláusulas tipo con variantes adaptadas a los tratados de inversión o mediante una convención de adhesión facultativa que tomara como modelo la Convención de Mauricio sobre la Transparencia en

$63 \mathrm{Al}$ respecto, véase el informe del Grupo de Trabajo III sobre la labor realizada en su $37 .^{\circ}$ periodo de sesiones (9 de abril de 2019) documento A/CN.9/970, p. 16. https://undocs.org/en/A/CN.9/970; el informe del Grupo de Trabajo III sobre la labor realizada en su 38. ${ }^{\circ}$ periodo de sesiones $(23 \mathrm{de}$ octubre de 2019) documento A/CN.9/1004, p. 20. https://undocs.org/en/A/CN.9/1004.

64 Nota de la Secretaría de la CNUDMI sobre las posibles reformas al sistema de solución de controversias entre inversionistas y Estados en materia de financiación de terceros (2 de agosto de 2019) documento A/CN.9/WG.III/WP.172, p. 11. https://undocs.org/en/A/CN.9/WG.III/WP.172 
los Arbitrajes entre Inversionistas y Estados en el Marco de un Tratado y la Convención Multilateral de la OCDE para Aplicar las Medidas Relacionadas con los Tratados Fiscales para Prevenir la Erosión de las Bases Imponibles y el Traslado de Beneficios. El Grupo de Trabajo también podría considerar la necesidad de elaborar disposiciones legales modelo sobre esta cuestión (traducción libre). ${ }^{65}$

\section{CONCLUSIONES}

Como hemos podido detallar a lo largo de este artículo, el TPF es un fenómeno que, a pesar de las críticas y visiones negativas que genera en algunos sectores, ha logrado convertirse en una realidad palpable en la práctica del arbitraje internacional. Este mecanismo, por el cual se pueden financiar los altísimos costos de los procedimientos arbitrales, es una herramienta óptima para lograr el acceso a la justicia de muchos actores que se ven enfrentados a su condición económica como una barrera para iniciar un arbitraje, o bien para aquellos que simplemente no desean destinar sus recursos en él. Sin embargo, sus virtudes no opacan el hecho de que la figura también genera ciertos inconvenientes, respecto a los cuales debe existir un debate amplio con miras a encontrar soluciones prácticas a los mismos. Justamente, nosotros hemos identificado la tendencia regulatoria que está viviendo el TPF, la cual podría dar respuesta a muchas de las dudas que aún existen sobre el financiamiento de terceros.

Por supuesto, el futuro del TPF estará marcado por un crecimiento exponencial en su uso y en su consolidación en nuevos mercados, máxime si se piensa que el fenómeno no ha dado muestras de una tendencia contraria. No obstante, creemos que la característica más notable sobre el TPF en los tiempos venideros será la proliferación, cada vez mayor, de regulaciones sobre la figura como hasta el momento ha ocurrido en los últimos diez años; además, la regulación no solo parece ser el futuro del TPF en el escenario del arbitraje internacional, sino también la garantía de un porvenir próspero de la figura. En específico, esta tendencia reporta tres grandes beneficios, los cuales son que permite contar con una identidad medianamente universal y generalizada del TPF; logra la validez de los acuerdos de financiación en jurisdicciones donde la práctica es prohibida al día de hoy o, incluso, en relación al ISDS donde se ha propuesto

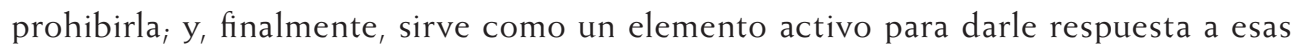
críticas más fuertes que existen en contra de la financiación por terceros.

Así, teniendo en cuenta que en los últimos diez años la tendencia regulatoria sobre el TPF creció rápida y vigorosamente, podemos esperar que al 2030 esta esté mucho más consolidada, dejando así su etapa de "infancia" para llegar a una edad adulta. Es probable que encontremos más autorregulaciones, soft law, legislaciones domésticas o reglamentos de arbitraje de instituciones arbitrales que hayan regulado la figura como 
las que hasta el momento hemos identificado; pero lo más importante de todo es que estas regulaciones seguramente serán cada vez más íntegras y detalladas, permitiéndole a la comunidad arbitral del futuro que se enfrente al fenómeno del TPF ostentar unas reglas claras, generalizadas y útiles sobre la figura en cuestión.

\section{REFERENCIAS}

AbDel WaHAB, M. (2019). Costs in International Arbitration: Navigating Through the Devil's Sea. En J. Engelmayer y M. Abdel RaOuf (eds.), Evolution and Adaptation: The Future of International Arbitration. International Council for Commercial Arbitration \& Kluwer Law International (pp. 465-503).

Affaki, B. (2013). A Financing is a Financing is a Financing. En B. Cremades Sanz Pastor y

A. DimolitsA (eds.), Third-Party Funding in International Arbitration. International Chamber of Commerce (pp. 10-15).

ALF (s. f.). Code of Conduct. Association of Litigation Funders. https://associationoflitigationfunders.com/code-of-conduct/

Bajaj, G., Yang, E. y Chan, Q. (2020, 11 de junio). Third-party funding in the Asia-Pacific region. Global Arbitration Review. https:/globalarbitrationreview.com/chapter/1227826/ third-party-funding-in-the-asia-pacific-region

BAO, C. (2017). Third Party Funding in Singapore and Hong Kong: The Next Chapter. Journal of International Arbitration, 34(3): 387-400.

Barrington, L. (2017). Third-Party Funding and the International Arbitrator. En P. SHAuGHNESSY y S. TUNG (eds.), The Powers and Duties of an Arbitrator: Liber Amicorum (pp. 15-24). Pierre A. Karrer. Kluwer Law International.

Baumann, A. y Singh, M. (2018). New Forms of Third-Party Funding in International Arbitration: Investing in Case Portfolios and Financing Law Firms. Indian Journal of Arbitration Law, $\operatorname{VII}(2):$ 29-44.

BeEchey, J. (2019). The Pandora's Box of Third-Party Funding: Some Practical Suggestions for Arbitrators in Light of Recent Developments. En J. ENGELMAYER y M. AbDEL RAOUF (eds.), Evolution and Adaptation: The Future of International Arbitration. International Council for Commercial Arbitration \& Kluwer Law International (pp. 558-586).

Bench NieuwVeld, L. y Shannon Sahani, V. (2017). Third-Party Funding in International Arbitration. Kluwer Law International.

Bogart, C. (2013). Overview of Arbitration Finance. En B. Cremades Sanz Pastor y A. DimOLITSA (eds.), Third-Party Funding in International Arbitration. International Chamber of Commerce (pp. 50-56).

BOGART, C. (2017). Third-Party Financing of International Arbitration. b-Arbitra | Belgian Review of Arbitration (2), 315-325.

BOWMAN, C., HuRFORD, K. y KHOURI, S. (2011). Third party funding in international commercial and treaty arbitration-a panacea or a plague? A discussion of the risks and benefits of third party funding. Transnational Dispute Management (4), 1-15. 
Brekoulakis, S. y Von Goeler, J. (2017). The Arbitration Agreement and Arbitrability, It's all about the Money: The Impact of Third-Party Funding on Costs Awards and Security for Costs in International Arbitration. En KlausegGer, C., Klein, P. et al. (eds.), Austrian Yearbook on International Arbitration. Manz'sche Verlags- und Universitätsbuchbandlung; Manz'sche Verlags-und (pp. 1-19).

Brown de Vejar, K. y Baldwin, C. (2019). The Economics of Access: Systemic Imbalances in ISDS. En J. EngelmaYer y M. AbDel RaOuf (eds.), Evolution and Adaptation: The Future of International Arbitration. International Council for Commercial Arbitration \& Kluwer Law International (pp. 520.557).

Burghetto, M. (2020). Risk Assessment and Third-Party Funding in Investment Arbitration.

En K. FACH GÓmEZ (ed.), Private Actors in International Investment Law: Beyond Claimants, Respondents and Arbitrators, European Yearbook of International Economic Law (EYIEL) (pp. 81-102).

Camayo Ortiz, S. (2020). Third-Party Funding y Conflictos de Interés de los Árbitros en el Arbitraje Internacional. Revista Arbitraje Alumni, (1), 80-105.

Cheng-Yee, K., Lespérance, A., MacGrath, D. y Hossain, N. (2020). Third-Party Funding and COVID-19. En M. SCHERER y N. BASSIRI et al. (eds.), International Arbitration and the COVID-19 Revolution. Kluwer Law International (pp. 179-190).

Clanchy, J. (2016). Navigating the Waters of Third Party Funding in Arbitration. Arbitration: The International Journal of Arbitration, Mediation and Dispute Management, 82(3), 222-232.

Clanchy, J. (2017, 9 de enero). Rigorous steps short of champerty: the Excalibur standard for control by funders. LexisNexis. https://www.lexisnexis.co.uk/blog/dispute-resolution/ rigorous-steps-short-of-champerty-the-excalibur-standard-for-control-by-funders

Commission, J. (2016, 29 de febrero). How Much Does an ICSID Arbitration Cost? A Snapshot of the Last Five Years. Kluwer Arbitration Blog. http://arbitrationblog.kluwerarbitration. com/2016/02/29/how-much-does-an-icsid-arbitration-cost-a-snapshot-of-the-last-fiveyears/?doing_wp_cron=1596332421.2208359241485595703125

Cremades, B. (2012). Third Party Litigation Funding: Investing in Arbitration. Spain Arbitration Review | Revista del Club Español del Arbitraje, (3), 155-187.

Cremades Sanz, Pastor B. (2013). Concluding remarks. En B. Cremades Sanz Pastor y A. Dimolitsa (eds.), Third-Party Funding in International Arbitration. International Chamber of Commerce (pp. 153-156).

Darwazeh, N. y Leleu, A. (2016). Disclosure and Security for Costs or How to Address Imbalances Created by Third-Party Funding. Journal of International Arbitration, 33(2), 125-150.

Derains, Y. (2013). Foreword. En B. Cremades Sanz Pastor y A. Dimolitsa (eds.), ThirdParty Funding in International Arbitration. International Chamber of Commerce (pp. 5-6).

Dos SANTOS, C. (2017). Third-party funding in international commercial arbitration: a wolf in sheep's clothing? ASA Bulletin, 35(4), 918-936.

FELER, A. (2015). Soft Law como herramienta de adecuación del Derecho Internacional a las nuevas coyunturas. Lecciones y Ensayos, (95), 281-303.

FERNÁNDEZ MASIÁ, E. (2016). La financiación por terceros en el arbitraje internacional. Cuadernos de Derecho Transnacional, 8(2), 204-220. 
FRANCK, S. (2019). Arbitration Costs: Myths and Realities in Investment Treaty Arbitration. Oxford University Press.

FRIGNATI, V. (2016). Ethical implications of third-party funding in international arbitration. Arbitration International, 32(3), 505-522.

FuCHS, A. y Richman, L. (2020). The Arbitration Agreement and Arbitrability, Third-party Funding in International Arbitration: A Comparative Analysis. En C. KLAUSEGGer y P. KLEIN et al. (eds.), Austrian Yearbook on International Arbitration 2020. Manz'sche Verlags \& Universitätsbuchbandlung (pp. 73-100).

Garino Podestá, J. y PicArdo GonZÁlez, S. (2019). Acceso a la justicia, prácticas abusivas y el paraíso de los apostadores: Third Party Funding en la práctica arbitral internacional. Revista de Derecho, 18(35), 39-60.

Geisker, J. y Luff, D. (2019). Australia. En L. Perrin (ed.), The Third Party Litigation Funding Law Review, Law Business Research, United Kingdom (pp. 1-20).

Gitman, L. y JoeHnK, M. (2009). Fundamentos de inversiones. Pearson Educación de México.

Goldsmith, A. y Melchionda, L. (2012). Third party funding in international arbitration: Everything you ever wanted to know (but were afraid to ask). International Business Law Journal, (1), 53-76.

GÜven, B., LOCKHART, K. y García, M. (2020). Regulating Third-Party Funding in InvestorState Arbitration Through Reform of ICSID and UNCITRAL Arbitration Rules: Holding Global Institutions to Their Development Mandates. En A. ANDERSOn y B. BEAUMONT (eds.), The Investor-State Dispute Settlement System: Reform, Replace or Status Quo? (pp. 287-318). Kluwer Law International.

Hashu, K. (2016). Third-Party Funding in International Arbitration: Regulating the Treacherous Trajectory. Asian International Arbitration Journal, 12(2), 77-106.

Hendel, C. (2010). Third Party Funding. Spain Arbitration Review I Revista del Club Español del Arbitraje, (9), 67-81.

Henriques, D. (2017). Third-Party Funding: A Protected Investment? Spain Arbitration Review I Revista del Club Español del Arbitraje, (30), 100-140.

Henriques, D. (2019). Arbitrating Disputes "in" Third-Party Funding. Arbitration: The International Journal of Arbitration, Mediation and Dispute Management, 85(2), 169-184.

Hirst, P. y Yeow, M. (2019, 4 de febrero). Comparing Hong Kong Code of Practice for Third Party Funding Arbitration with the Code of Conduct in England \& Wales. Kluwer Arbitration Blog. http://arbitrationblog.kluwerarbitration.com/2019/02/04/comparinghong-kong-code-of-practice-for-third-party-funding-arbitration-with-the-code-ofconduct-in-england-wales/

Hou, P. (2018). Financing arbitration in mainland China: Hong Kong's legislation as a model. Arbitration International, 34(4), 593-623.

IBISWorld (2020, 29 de mayo). Litigation Funding in Australia. IBISWorld. https://www.ibisworld. com/au/industry/litigation-funding/5446/

Kalajdzic, J., Cashman, P. y Longmoore, A. (2013). Justice for Profit: A Comparative Analysis of Australian, Canadian and U.S. Third Party Litigation Funding. The American Journal of Comparative Law, 61(1), 93-148. 
Kamnani, P. y Kaushal, A. (2019). Regulation of Third Party Funding of Arbitration in India: The Road Not Taken. Indian Journal of Arbitration Law, VIII(2), 151-165.

KARL, A. (2020). Investment Arbitration, Security for Costs as a Default in Investment Arbitration: A Workable Protection for States when Third-Party Funders are involved? En C. Klausegger y P. Klein et al. (eds.), Austrian Yearbook on International Arbitration 2020 (pp. 563-592). Manz'sche Verlags- \& Universitätsbucbbandlung.

KirTley, W. y WietrZyKOWSKi, K. (2013). 'Should an Arbitral Tribunal Order Security for Costs When an Impecunious Claimant Is Relying upon Third-Party Funding? Journal of International Arbitration, 30(1), 17-30.

Kreindler, R. y Goldsmith, A. (2019). Should Parties Disclose the Existence of a ThirdParty Funder? (Disclosure and Conflicts of Interest). En S. TUNG y F. FORTESE et al. (eds.), Finances in International Arbitration: Liber Amicorum Patricia Shaugbnessy (pp. 255-272).

KruG, Z. y EATOCK, H. (24 de septiembre de 2018). Snapshot on Litigation Finance in Latin America. Kluwer Arbitration Blog. http://arbitrationblog.kluwerarbitration. com/2018/09/24/snapshot-on-litigation-finance-in-latin-america/

LAMm, C. y HellbeCK, E. (2013). Third-Party Funding in Investor-State Arbitration: Introduction and Overview. En B. Cremades Sanz Pastor y A. Dimolitsa (eds.), Third-Party Funding in International Arbitration. International Chamber of Commerce (pp. 101-121).

Lefevre, F., Callens, P. y Croisant, G. (2017). Legality of third-party funding mechanisms under Belgian law. b-Arbitra | Belgian Review of Arbitration (1), 35-65

LEW, J. (2019). Costs in International Arbitration: Can Costs Be Controlled? En S. TunG y F. FORTESE et al. (eds.), Finances in International Arbitration: Liber Amicorum Patricia Shaughnessy (pp. 291-298). Kluwer Law International.

Livschitz, T. (2018). Third Party Funding in Arbitration. En M. ArRoYO (ed.) Arbitration in Switzerland: The Practitioner's Guide (Second Edition) (pp. 2615-2632). Kluwer Law International.

Maciel, M. y Villarpando PéreZ, A. (2020). Financiación por Terceros en el Arbitraje Internacional: Soluciones prácticas para su intervención. Revista Arbitraje Alumni, (1), 62-80.

Marquais, O. y GreC, A. (2020). Do's and Dont's of Regulating Third-Party Litigation Funding: Singapore vs. France. Asian International Arbitration Journal, 16(1), 49-68.

MATRaY, D. y VAN Rompaey, S. (2017). An introduction to third-party funding. b-Arbitra I Belgian Review of Arbitration, (1), 175-194.

MAZZONI, A. (2019). Third-Party Funding in International Arbitration: Views from a Conflictof-Law Perspective and Beyond. En S. Tung y F. FORTESE et al. (eds.), Finances in International Arbitration: Liber Amicorum Patricia Shaugbnessy. Kluwer Law International (pp. 299-322).

Mereminskaya, E. (2017). Financiamiento de Litigios a Través de Terceros y su Aterrizaje en Chile. Informativo On-Line Centro de Arbitraje y Mediación - CAM Santiago, (3), 1-11. http:// www.camsantiago.cl/informativo-online/2017/01/

Milburn, R. (2019, 2 de febrero). Enabling Legislation: Check ${ }_{i}$ Code of Practice for Third Party Funders: Check; Third Party Funding for Arbitration in Hong Kong is Ready for Lift Off! Kluwer Arbitration Blog. http://arbitrationblog.kluwerarbitration.com/2019/02/02/ enabling-legislation-check-code-of-practice-for-third-party-funders-check-third-partyfunding-for-arbitration-in-hong-kong-is-ready-for-lift-off/ 
MontPetit, E. (2018). British Columbia Amends and Modernizes International Commercial Arbitration Act. ADR Institute of Canada. https://adric.ca/adr-perspectives/britishcolumbia-amends-and-modernizes-international-commercial-arbitration-act/

NajAR, J. (2013). How to Mitigate Legal and Arbitration Costs: Considerations by a User. En A. VAN DEN BERG (ed.), International Arbitration: The Coming of a New Age? International Council for Commercial Arbitration \& Kluwer Law International (pp. 305-320).

Nathan, R., Gómez, R., Mogan, K. y Lee, A. (2020, 18 de agosto). International Arbitration 2020: Malaysia. Chambers and Partners. https://practiceguides.chambers.com/practiceguides/international-arbitration-2020/malaysia

NAVARro, S. (2014). Cuestiones relativas al third party funding en arbitraje. Arbitraje: Revista de Arbitraje Comercial y de Inversiones, 7(3), 801-805.

Osmanoglu, B. (2015). Third-Party Funding in International Commercial Arbitration and Arbitrator Conflict of Interest. Journal of International Arbitration, 32(3), 325-350.

PARK, W. y Rogers, C. (2015). The Arbitration Agreement and Arbitrability, Third-Party Funding in International Arbitration: The ICCA Queen-Mary Task Force. En C. KLAUSEGGER y P. KLEIN et al. (eds.), Austrian Yearbook on International Arbitration 2015. Manz'sche Verlags- und Universitätsbucbbandlung; Manz'sche Verlags- und (pp. 113-123).

PIzarro, C. (2017). ¿Tres son multitud? Algunas notas sobre el Third Party Funding y su aplicación en arbitrajes comerciales. Revista Ius et Veritas, (54), 236-243.

Popova, I. y SEIFERT, K. (2020). Gatekeeping, Lawmaking, and Rulemaking: Lessons from Third-Party Funding in Investment Arbitration. En K. FACH GÓMEZ (ed.), Private Actors in International Investment Law: Beyond Claimants, Respondents and Arbitrators, European Yearbook of International Economic Law (EYIEL). Springer, pp. 133-155.

RAMESH, S. (2020). Third-Party Funding in International Arbitration: Ownership of the Claim, Consequences for Costs Orders, and Regulation. Arbitration International, 36 (2), 275-295.

RamíReZ, C. (2018). Latin America and Third Party Funding: A Growing Phenomenon. Funding in Focus VI: 47-51.

Rogers, J., Fitzgerald, A. y Dowling, C. (2017). Emerging approaches to the regulation of Third-Party funding. International Arbitration Report, (9): 29-31.

Rosenfeld, F. (2016). Security for costs in ICSID arbitration: RSM Production Corporation v St Lucia. Arbitration International, 32(1), 157-166.

RuedA-GarcíA, J. (2020). Third-Party Funding and Access to Justice in Investment Arbitration: Security for Costs as a Provisional Measure or a Standalone Procedural Category in the Newest Developments in International Investment Law. En K. FACH GÓMEZ (ed.), Private Actors in International Investment Law: Beyond Claimants, Respondents and Arbitrators, European Yearbook of International Economic Law (EYIEL) (pp. 103-121).

Scherer, M., Goldsmith, A. y FlèChet, C. (2012). Third party funding in international arbitration in Europe: Part 1-funders' perspectives. International Business Law Journal, (2): 207-220.

Secomb, M., Wallin, A. y Richmond, G. (2019). Singapore. En L. Perrin (ed.), The Third Party Litigation Funding Law Review, Law Business Research, United Kingdom (pp. 171-182). 
SEIDEL, S. (2013). Third-party investing in international arbitration claims to invest or not to invest? A daunting question. En B. SAnZ PAstor y A. Dimolitsa (eds.), Third-Party Funding in International Arbitration. International Chamber of Commerce (pp. 16-31).

ShannOn SaHANI, V. (2013). Recent Developments in Third-Party Funding. Journal of International Arbitration, 30(4), 443-452.

Shannon Sahani, V. (2020). Addressing Financial Access to Justice in Investment Treaty Arbitration. En A. Anderson y B. Beaumont (eds.), The Investor-State Dispute Settlement System: Reform, Replace or Status Quo? Kluwer Law International (pp. 271-286).

SHAW, G. (2017). Third-party funding in investment arbitration: how non-disclosure can cause harm for the sake of profit. Arbitration International, 33(1), 109-120.

Sim, C. (2017). Security for Costs in Investor-State Arbitration. Arbitration International, 33(3), 427-495

Solas, G. (2019). Third Party Funding: Law, Economics and Policy. Cambridge University Press.

SteinitZ, M. (2011). Whose Claim Is This Anyway? Third Party Litigation Funding. Minnesota Law Review 95(4), 1268-1338.

Stoyanov, M. y OwCZAREK, O. (2015). Third-Party Funding in International Arbitration: Is it Time for Some Soft Rules? BCDR International Arbitration Review, 2(1), 171-200.

The Government of the Hong Kong Special Administrative Region (7 de diciembre de 2018) Code of Practice for Third Party Funding of Arbitration issued. The Government of the Hong Kong Special Administrative Region, Press Releases. https://www.info.gov.hk/gia/ general/201812/07/P2018120700601.html

Theoduloz, S. (2019). "Third Party Funding"; su relevancia e influencia actual en el mundo del arbitraje internacional. Revista de Derecho, (20), 159-187.

Veljanovski, C. (2012). Third Party Litigation Funding in Europe. Journal of Law, Economics and Policy, 8(3), 405-450.

VILla, F. (2014). Le financement de contentieux par des tiers (Third Party Funding). Anwalts Revue De L'Avocat, (5), 207-211.

VOn Goeler, J. (2016). Third-Party Funding in International Arbitration and its Impact on Procedure. Kluwer Law International.

Walck, R. (2020). A Quantum Expert's Perspective on Third-Party Funding. En K. FaCH GÓmez (ed.), Private Actors in International Investment Law: Beyond Claimants, Respondents and Arbitrators, European Yearbook of International Economic Law (EYIEL) (pp. 123-131).

WheAl, R. y BRUmpton, P. (2016, 25 de noviembre). Excalibur Litigation: Court of Appeal Confirms that Funders Will Be Put to the Sword. White \& Case. https://www.whitecase.com/ publications/alert/excalibur-litigation-court-appeal-confirms-funders-will-be-put-sword

YEOH, D. (2016). Third Party Funding in International Arbitration: A Slippery Slope or Levelling the Playing Field? Journal of International Arbitration, 33(1), 115-122.

T3 Lista de documentos citados

Centro Internacional de Arreglo de Diferencias Relativas a Inversiones (2018). Propuesta de Enmiendas a las Reglas del CIADI-Documento de Trabajo. Centro Internacional de Arreglo de Diferencias Relativas a Inversiones. https://icsid.worldbank.org/sites/default/ files/WP1_Amendments_Vol_3_WP-updated-9.17.18.pdf. 
Centro Internacional de Arreglo de Diferencias Relativas a Inversiones (2020). Propuesta de Enmiendas a las Reglas del CIADI-Documento de Trabajo número 4. Centro Internacional de Arreglo de Diferencias Relativas a Inversiones. https://icsid.worldbank.org/sites/ default/files/amendments/WP_4_Vol_3_Sp.pdf.

Informe del Grupo de Trabajo III sobre la labor realizada en su 34..$^{\circ}$ periodo de sesiones (19 de diciembre de 2017). Documento A/CN.9/930/Rev.1. https://undocs.org/en/A/CN.9/930/ Rev.1

Informe del Grupo de Trabajo III sobre la labor realizada en su 35..$^{\circ}$ periodo de sesiones (14 de mayo de 2018). Documento A/CN.9/935. https://undocs.org/es/A/CN.9/935

Informe del Grupo de Trabajo III sobre la labor realizada en su $36 .^{\circ}$ periodo de sesiones ( 6 de noviembre de 2018). Documento A/CN.9/964. https://undocs.org/en/A/CN.9/964

Informe del Grupo de Trabajo III sobre la labor realizada en su 37. ${ }^{\circ}$ periodo de sesiones (9 de abril de 2019). Documento A/CN.9/970. https://undocs.org/en/A/CN.9/970

Informe del Grupo de Trabajo III sobre la labor realizada en su $38 .^{\circ}$ periodo de sesiones (23 de octubre de 2019). Documento A/CN.9/1004. https://undocs.org/en/A/CN.9/1004

International Council for Commercial Arbitration \& Queen Mary University of London (2018). Report of the ICCA-Queen Mary Task Force on Third-Party Funding in International Arbitration. International Council for Commercial Arbitration. https://www.arbitrationicca.org/icca-reports-no-4-icca-queen-mary-task-force-report-third-party-funding

Lord Neuberger (2013). From Barretry, Maintenance and Champerty to Litigation. Harbour Litigation Funding First Annual Lecture, Londres, pp. 1-25. https://www.supremecourt. uk/docs/speech-130508.pdf

Nota de la Secretaría de la CNUDMI sobre las posibles reformas al sistema de solución de controversias entre inversionistas y Estados en materia de financiación de terceros $(2$ de agosto de 2019). Documento A/CN.9/WG.III/WP.172. https://undocs.org/en/A/CN.9/ WG.III/WP.172

Queen Mary University of London y PricewaterhouseCoopers (2013). International Arbitration Survey, Corporate choices in International Arbitration: Industry perspectives. Pricewaterhouse Coopers. http://www.arbitration.qmul.ac.uk/media/arbitration/docs/ pwc-international-arbitration-study2013.pdf.

Queen Mary University of London y White \& Case (2015). International Arbitration Survey: Improvements and Innovations in International Arbitration. White \& Case. https://www. whitecase.com/sites/whitecase/files/files/download/publications/qmul-internationalarbitration-survey-2015_0.pdf.

Queen Mary University of London y White \& Case (2018). International Arbitration Survey: The Evolution of International Arbitration. White \& Case. https://www.whitecase. $\mathrm{com} /$ sites/whitecase/files/files/download/publications/qmul-international-arbitrationsurvey-2018-19.pdf

The Chartered Institute of Arbitrators (2011). CIArb Costs of International Arbitration Survey 2011. Chartered Institute of Arbitrators. https://www.international-arbitration-attorney. com/wp-content/uploads/2017/01/CIArb-Cost-of-International-Arbitration-Survey.pdf 
United Nations Conference on Trade and Development (2013). Recent Developments in Investor-State Dispute Settlement (ISDS). United Nations Conference on Trade and Development. https://unctad.org/system/files/official-document/webdiaepcb2013d3_en.pdf

\section{Lista de sentencias y laudos arbitrales citados}

Centro Internacional de Arreglo de Diferencias Relativas a Inversiones ( 8 de abril de 2016). Teinver S.A et al. vs. La República de Argentina, Caso CIADI n. ${ }^{\circ}$ ARB/09/1. http://icsidfiles. worldbank.org/icsid/ICSIDBLOBS/OnlineAwards/C520/DC7892_Sp.pdf

Centro Internacional de Arreglo de Diferencias Relativas a Inversiones (17 de noviembre de 2014). Giovanni Alemanni y otros vs. La República de Argentina, Caso CIADI n. ${ }^{\circ}$ ARB/07/8. http://icsidfiles.worldbank.org/icsid/ICSIDBLOBS/OnlineAwards/C100/DC5132_Sp.pdf

Corte de Apelaciones de Inglaterra y Gales (18 de noviembre de 2016). Excalibur Ventures vs. Texas Keystone and Others, [2016] EWCA Civ 1144. https://www.bailii.org/ew/cases/ EWCA/Civ/2016/1144.html.

Corte de Apelaciones de Inglaterra y Gales (30 de julio de 1962). Re Trepca Mines Ltd, [1963] Ch. 199. https://uk.practicallaw.thomsonreuters.com/D-017-1855?transitionType=Defa ult\&contextData $=($ sc. Default $) \&$ firstPage $=$ true

Corte Permanente de Arbitraje (11 de junio de 2016). South American Silver vs. El Estado Plurinacional de Bolivia, Caso CPA n. ${ }^{\circ}$ 2013-15. https://www.italaw.com/sites/default/ files/case-documents/italaw7176.pdf

Corte Permanente de Arbitraje (20 de junio de 2018). Manuel García Armas et al. vs. La República Bolivariana de Venezuela, Caso CPA n. ${ }^{\circ}$ 2016-08. https://www.italaw.com/sites/ default/files/case-documents/italaw9849_2.pdf

Corte Suprema de Nueva Zelanda (20 de septiembre de 2013). Waterhouse vs. Contractors Bonding Limited, [2013] NZSC 89. https://www.courtsofnz.govt.nz/cases/waterhouse$\mathrm{v}$-contractor-bonding-ltd

Suprema Corte de Justicia de Irlanda (23 de mayo de 2017). Persona Digital Telephony Ltd and another vs. The Minister for Public Enterprise, Ireland and Others, [2017] IESC 27. https://www.bailii.org/ie/cases/IESC/2017/S27.html

\section{Listado de normativas y regulaciones citadas}

Code of practice for Third Party Funding of Arbitration de Hong Kong del 2018. https:// www.info.gov.hk/gia/general/201812/07/P2018120700601.htm

Código de Buenas Prácticas Arbitrales del Club Español de Arbitraje. https://www.garrigues. com/sites/default/files/documents/codigo_de_buenas_practicas_arbitrales_del_club_espanol_del_arbitraje.pdf

Código de Conducta de la Association of Litigation Funders of England \& Wales. https:// associationoflitigationfunders.com/code-of-conduct/ 
Directrices de la International Bar Association sobre Conflictos de Intereses en Arbitraje Internacional del 2014. https://www.ibanet.org/Publications/publications_IBA_guides_and_free_materials.aspx

Ley de Arbitraje Comercial Internacional de la Columbia Británica de 1996 [RSBC 1996]. https:// www.bclaws.gov.bc.ca/civix/document/id/complete/statreg/96233_01\#: :text $=1 \% 20$ (1) \% $20 \mathrm{Th}$ is $\% 20 \mathrm{Act} \% 20$ applies, which \% 20 applies $\% 20$ in $\% 20 \mathrm{British} \% 20$ Columbia.\&text $=(\mathrm{c}) \% 20$ the $\% 20$ parties $\% 20$ have $\% 20$ expressly,to\%20more $\% 20$ than $\% 20$ one $\% 20$ state

Ley de Derecho Civil de Singapur del año 1999 [chapter 43]. https://sso.agc.gov.sg/Act/ CLA1909\#pr5B-

Ordenanza de Arbitraje de Hong Kong del 2011 [Cap. 609]. https://www.elegislation.gov.hk/ hk/cap609?tab=m\&xpid=ID_1498191921145_001

Ordenanza de Mediación de Hong Kong del 2012 [Cap. 620]. https://www.elegislation.gov. hk/hk/cap620?xpid=ID _1498202413400_001

Reglamento de arbitraje de inversiones del 2017 del Singapore International Arbitration Centre. https://www.siac.org.sg/images/stories/articles/rules/IA/SIAC\%20Investment\%20 Rules\%202017.pdf

Reglamento de arbitraje de inversiones del 2019 de la Beijing Arbitration Commission. https:// www.kluwerarbitration.com/

Reglamento de arbitraje del 2018 del Hong Kong International Arbitration Centre. https:// www.hkiac.org/sites/default/files/ck_filebrowser/PDF/arbitration/2018_hkiac_rules.pdf

Reglamento de arbitraje del 2020 de la Camera Arbitrale di Milano. https://www.cameraarbitrale.it/upload/documenti/arbitrato/ARBITRATION\%20RULES\%202020.pdf

Reglamento de arbitraje del 2020 del Centro Internacional de Arbitraje de Madrid. https:// madridarb.com/wp-content/uploads/2020/04/REGLAMENTO_CIAM_DIGITALDEF2.pdf

Resolución administrativa AR 18/2016 de la Centro de Arbitraje y Mediación de la Cámara de Comercio de Brasil-Canadá. https://ccbc.org.br/cam-ccbc-centro-arbitragem-mediacao/ en/administrative-resolutions/ar-18-2016-recommendations-regarding-the-existence-ofthird-party-funding-in-arbitrations-administered-by-cam-ccbc/ 